Fall 12-20-2019

\title{
Lifestyle Management for Vestibular Disorders
}

Michelle Pock

DOI: https://doi.org/10.46409/sr.DXLC2650

Follow this and additional works at: https://soar.usa.edu/capstones

Part of the Neurology Commons, Occupational Therapy Commons, and the Otolaryngology Commons

\section{Recommended Citation}

Pock, M. (2019). Lifestyle Management for Vestibular Disorders. [Doctoral project, University of St Augustine for Health Sciences]. SOAR @ USA: Student Capstone Projects Collection. https://doi.org/ 10.46409/sr.DXLC2650

This Capstone is brought to you for free and open access by the Student Research at SOAR @ USA. It has been accepted for inclusion in Student Capstone Projects by an authorized administrator of SOAR @ USA. For more information, please contact soar@usa.edu, erobinson@usa.edu. 


\title{
LIFESTYLE MANAGEMENT FOR VESTIBULAR DISORDERS
}

by

Michelle M. Pock

\author{
A Capstone Presented in Partial Fulfillment \\ of the Requirement for the Degree of \\ DOCTOR OF OCCUPATIONAL THERAPY \\ University of St. Augustine for Health Sciences
}

December 2019 


\section{LIFESTYLE MANAGEMENT FOR VESTIBULAR DISORDERS}

by

Michelle M. Pock

has been approved

December 2019

APPROVED:

Susan MacDermott, OTD, OTR/L, Doctoral Coordinator

Becki Cohill, OTD, OTR/L, Doctoral Coordinator

Erin Schwier, EdD, OTD, OTR/L, Program Director

\section{ACCEPTED AND SIGNED:}

\begin{tabular}{|c|c|}
\hline $\begin{array}{l}\text { Susan MacDermott, } \\
\text { OTD, OTR/L }\end{array}$ & $\begin{array}{l}\text { Digitally signed by Susan } \\
\text { MacDermott, OTD, OTR/L } \\
\text { Date: 2019.12.17 18:48:11 - } 08^{\prime} 00^{\prime} \\
\end{array}$ \\
\hline \multicolumn{2}{|c|}{ 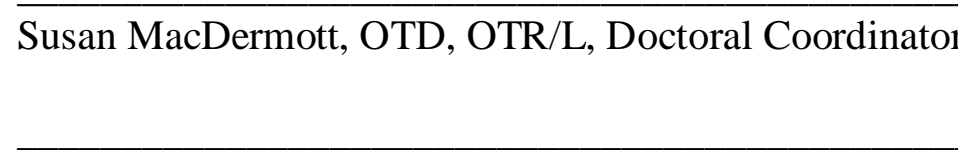 } \\
\hline \multicolumn{2}{|c|}{ Becki Cohill, OTD, OTR/L, Doctoral Coordinator } \\
\hline eschwier@usa.edu & 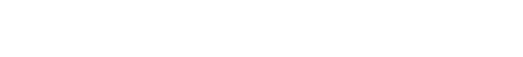 \\
\hline
\end{tabular}


Table of Contents

Chapter I: Introduction $\quad 5$

$\begin{array}{lr}\text { Background } & 5\end{array}$

$\begin{array}{ll}\text { Statement of Problem } & 7\end{array}$

$\begin{array}{ll}\text { Purpose Statement } & 7\end{array}$

$\begin{array}{ll}\text { Rationale for Proposed Project } & 7\end{array}$

$\begin{array}{lr}\text { Significance of Proposed Project } & 9\end{array}$

$\begin{array}{lr}\text { Preliminary Project Objectives } & 9\end{array}$

$\begin{array}{ll}\text { Definition of Terms } & 10\end{array}$

$\begin{array}{lr}\text { Assumptions, Limitations, and Delimitations } & 10\end{array}$

$\begin{array}{ll}\text { Chapter II: Literature Review } & 13\end{array}$

$\begin{array}{ll}\text { Current Role of Occupational Therapy in Vestibular Disorders } & 13\end{array}$

$\begin{array}{ll}\text { Lifestyle Factors and Management for Vestibular Disorders } & 13\end{array}$

$\begin{array}{ll}\text { Limitations in Current Treatment Options to Address Lifestyle Factors } & 14\end{array}$

$\begin{array}{ll}\text { Chapter III: Project Description } & 16\end{array}$

$\begin{array}{ll}\text { Participants } & 16\end{array}$

$\begin{array}{ll}\text { Methods } & 16\end{array}$

$\begin{array}{ll}\text { Procedures and Timelines } & 17\end{array}$

$\begin{array}{ll}\text { Project Description } & 18\end{array}$

$\begin{array}{ll}\text { Chapter IV: Results and Analysis } & 20\end{array}$

$\begin{array}{ll}\text { Results } & 20\end{array}$

$\begin{array}{ll}\text { Chapter V: Discussion } & 25\end{array}$

$\begin{array}{lr}\text { Chapter VI: Conclusion } & 28\end{array}$ 
$\begin{array}{ll}\text { Limitations } & 28\end{array}$

$\begin{array}{lr}\text { Implications for OT } & 28\end{array}$

$\begin{array}{lr}\text { Conclusion } & 29\end{array}$

$\begin{array}{ll}\text { References } & 30\end{array}$

$\begin{array}{ll}\text { APPENDIX A. Student Introduction Script } & 37\end{array}$

$\begin{array}{ll}\text { APPENDIX B. Participant Interview Questions } & 39\end{array}$

APPENDIX C. Interview Questions for Practitioners 41

APPENDIX D. Lifestyle Factors Chart 43

$\begin{array}{lr}\text { APPENDIX E. Online Survey } & 45\end{array}$

APPENDIX F. Weekly Presentation Example $\quad 47$

APPENDIX G. Lifestyle Management Program for Individuals with Vestibular Disorders 49

$\begin{array}{lr}\text { APPENDIX H. Site Presentation } & 115\end{array}$ 


\section{Chapter I: Introduction}

\section{Background}

The vestibular system, consisting of inner ear structures and the brain, shares sensory input about motion, equilibrium, and spatial orientation, with the visual and proprioceptive systems to help the body maintain balance (Vestibular Disorders Association, 2016). This system is imperative to be able to move around and carry out ones chosen activities of daily living at home and in the community (Gronski, Neville, Kannenberg, \& Cohen, 2017). Impairment at any point in this system can result from injury, infection, pressure changes, medication use, or unknown cause (Vestibular Disorders Association [VEDA], 2018). Vestibular impairment can lead to a variety of physical and psychological problems that impact quality of life. People with vestibular disorders often present with vertigo, nausea, hearing changes, unsteadiness, and visual disturbances that can be managed by medications, lifestyle changes, and vestibular rehabilitation (DynaMed Plus, 2018).

Approximately $35.4 \%$ of US adults over the age of 40 experience vestibular impairments (Agrawal, Carey, Della Santina, Schubert, \& Minor, 2009). The most common vestibular disorders include benign paroxysmal positional vertigo (BPPV), vestibular migraine, labyrinthitis or vestibular neuritis, and Ménière's disease (VEDA, 2018). BPPV, resulting from otoconia entering one or more of the semicircular canals, impacts daily activities and increases risk for falls (Bhattacharyya et al., 2017). Vestibular migraine involves vertigo and migraine symptoms; current prevention recommendations could include dietary, behavioral, and sleep changes (Hilton \& Shermetaro, 2019). Ménière's disease is characterized by attacks of a variety of symptoms including hearing loss, tinnitus, and vertigo; noninvasive treatments such as a sodium restriction diet have been found helpful (Koenen \& Andaloro, 2019). Vestibular neuritis 
involves an acute stage of severe vertigo, nausea, vomiting, and imbalance, followed by a longer period of imbalance (Goddard \& Fayad, 2011). While medications are used to manage vestibular neuritis in the acute stage, the chronic stage is aimed at minimizing the use of medications, compensation through vestibular rehabilitation, and continuing to move the head and body (Goddard \& Fayad, 2011).

Vestibular disorder symptoms impact daily life resulting in a need for lifestyle modification. People with vestibular disorders present with symptoms that can be provoked by the movements of daily activities, require increased time to complete routines, and often avoid participating in meaningful activities (Gronski, Neville, Kannenberg, \& Cohen, 2017). Vestibular impairment significantly increases risk of falls, which can be costly and increase a person's fear of moving (Agrawal, Carey, Della Santina, Schubert, \& Minor, 2009). Adults with vestibular disorders experience reduced engagement in valued activities such as gardening, performing household duties, reading, and using the computer (Killington et al., 2015). A qualitative study found that participants with vertigo and dizziness felt restricted in various aspects of life such as relationships, employment, and community engagement (Mueller, Schuster, Strobl, \& Grill, 2012). Driving may elicit vertigo and cause difficulty seeing fine details on the road and in the car (Hoffer, Balaban, \& Cohen, 2011). A lower prevalence of normal sleep was found in those with vestibular vertigo, which may have to do with the vestibular system providing cues for sleep initiation and maintenance (Albathi, \& Agrawal, 2017). Finally, many adults with vestibular disorders experience anxiety and depression (Naber et al., 2011).

Entry-level occupational therapy practitioners have the knowledge to treat individuals with vestibular disorders through functional mobility training, modification of environments, 
recommendation of assistive devices, and routine management to control symptoms; advancedlevel practitioners utilize vestibular rehabilitation therapy (Gronski, Neville, Kannenberg, \& Cohen, 2017).

\section{Statement of Problem}

The symptoms accompanying vestibular disorders can greatly reduce a person's quality of life. People with vestibular disorders have concerns that impact lifestyle including limiting activities of daily living, limiting participation in social events, difficulty driving, and difficulty working (Hoffer, Balaban, \& Cohen, 2011; Mueller, Schuster, Strobl, \& Grill, 2012; Honaker \& Kretschmer, 2014). While occupational therapists are qualified to provide services to sustain and improve the occupational performance of people with vestibular disorders, occupational therapy is not well represented in this area particularly in addressing lifestyle components for vestibular disorders.

\section{Purpose Statement}

This project aims to identify lifestyle factors impacted by and contributing to vestibular symptoms, promote health and well-being, and increase engagement in the person's chosen occupations through participation in a lifestyle management program. This will be done through identifying symptom provoking activities, modification and adaptation of lifestyle factors, and using occupations as a means to manage symptoms.

\section{Rationale for Proposed Project}

There is a small amount of literature addressing vestibular disorders and the importance of addressing occupations authored by occupational therapists (Cohen, 2014; Cohen, Miller, Kane-Wineland, \& Hatfield, 1995; Hoffer, Balaban, \& Cohen, 2011). There is growth available for evidence on lifestyle factors and functional performance of people with vestibular disorders. 
Occupational therapists are able to help people with vestibular disorders by task analyzing symptom provoking activities, assessing the impact of symptoms on occupations, providing adaptations, and providing ways to modify environments (Gronski, Neville, Kannenberg, \& Cohen, 2017).

Vestibular disorders have factors that can impact all areas of life. Lifestyle Redesign® is an evidence-based intervention approach from the University of Southern California that promotes health and well-being through a personalized and sustainable plan that addresses chronic disease risk factors (Clark, 2015). The intervention, built upon the USC Well Elderly Studies, involves selecting client-centered activities, making routine changes, and practicing healthy habits and routines (Clark, 2015). This theoretical approach will be used to guide development of a lifestyle modification program. Lifestyle Redesign ${ }^{\circledR}$ has not yet been applied to the vestibular population, however Lifestyle Redesign ${ }^{\circledR}$ interventions have been applied to other populations with chronic disease. For example, the intervention was applied to people living with chronic pain and was shown to be effective in increasing quality of life and engaging in functional activities (Simon \& Collins, 2017).

The Model of Human Occupation (MOHO) is a holistic approach that emphasizes the internal and external interactions of a person regarding their occupational performance (Cole \& Tufano, 2008). MOHO views the person as an open system interacting with the environment with hierarchical subsystems of volition, habituation, and performance; dysfunction of one of these subsystems affects the other two (Kielhofner \& Burke, 1980). The interaction between the person and the environment is known as occupation and where change occurs (Kielhofner \& Burke, 1980). Volition is made up of values, interests, and personal causation (Kielhofner \& Burke, 1980). Habituation involves habits, routines, and roles functioning to organize 
occupations (Kielhofner \& Burke, 1980). Performance consists of skills which produce action (Kielhofner \& Burke, 1980). For people with vestibular disorders, dysfunction lies in the subsystem of habituation because of the impact vestibular symptoms have on routines. Through the lens of this model, implementation of healthy routines can have a positive impact on vestibular symptoms. Program development will focus on redefining routines related to lifestyle changes in order to maximize the person's ability to perform their occupations with their disorder.

\section{Significance of Proposed Project}

Cheng et al (2012) found individuals with chronic dizziness, including those with vestibular hypofunction, BPPV, and Meniere's disease, had poor quality of life in terms of physical and social functioning, role limitation, and vitality. The proposed project aims to provide people with individualized, client-centered approaches to living well with their vestibular disorder. The proposed project will aim to increase the quality of life in adults living in the community with common vestibular disorders through the participation in a lifestyle management program. The program may help grow occupational therapy's role in treating individuals with vestibular disorders and in prevention of symptoms through lifestyle modification.

\section{Preliminary Project Objectives}

The preliminary project objectives include:

1. Identify common lifestyle factors that impact vestibular symptoms and can support management of symptoms of people with vestibular disorders through literature search, interviews with key experts in the field, observation at sites that treat clients with vestibular disorders, and participant interviews. 
2. Develop and propose a program that addresses and promotes lifestyle modification in people with vestibular disorders.

3. Assess opportunities and barriers for current OT role in vestibular settings.

4. Advocate for OT role in prevention and management of lifestyle concerns for vestibular populations.

\section{Definition of Terms}

Lifestyle will refer to the characteristics, behaviors, and functions of individuals that influence their physical and mental health (Farhud, 2015). Lifestyle factors may include diet, physical activity, sleep, leisure, work, relationships, etc.

Vertigo will refer to the spinning or falling sensation a person feels when they are not moving (VEDA, 2018).

Vestibular rehabilitation will refer to treatment targeting vestibular disorders using maneuvers, muscle strengthening, vestibular-ocular techniques, vestibular-cervical stabilization, and physical exercises aimed at the development of habituation, adaptation, and substitution (Boyer et al., 2008).

Quality of life will refer to health quality of life. Health quality of life measures general well-being in relation to participation in physical activities and social activities, participation in usual role activities, mental health, emotional health, and vitality (Bagwell, 2018).

\section{Assumptions, Limitations, and Delimitations}

There are factors that need to be considered related to this project that are in and out of reasonable control. One underlying assumption is that addressing and promoting lifestyle modification is not already being done by another discipline. For example, according to the American Physical Therapy Association, physical therapy scope of practice includes helping 
“individuals maintain, restore, and improve movement, activity, and functioning, thereby enabling optimal performance and enhancing health, well-being, and quality of life" (American Physical Therapy Association, 2019). This type of intervention may be under the scope of other professions' practice; however, it is being assumed that these disciplines are focusing on other methods of treatment. The training and practice patterns of vestibular rehabilitation therapists are found to be highly variable and not standardized (Cohen, Kim, Graziano, Malmstrom, \& Sharpe, 2009). To ensure the development of the program is not a repetition of services already being provided, a focus may be held on distinguishing the differences between occupational therapy and other disciplines, encouraging an interdisciplinary approach, and providing education to other staff.

A limitation of this project includes the time needed to observe and interview clients with vestibular disorders. For example, taking time away from a client's physical therapy session to interview them may not be appropriate, and clients may not have additional time to talk after their sessions. Due to the setting, another limitation is the experiences of participants will be limited to those who are receiving physical therapy treatments. Observations of clients made during therapy sessions as well as interviewing experts in the field will be used to gain a broad picture of the needs of this population despite the time and place constraints.

Delimitations include the population chosen, using the theoretical perspectives from Lifestyle Redesign ${ }^{\circledR}$ and the $\mathrm{MOHO}$, the clinic setting where observations are occurring, and the qualitative approach to obtaining information. The population of people with vestibular disorders was further defined to adults with the four most common vestibular disorders and ones that would potentially benefit from lifestyle changes. A physical therapy clinic setting was chosen because it is a traditional setting where clients with common vestibular disorders receive 
treatment. The theoretical perspectives were chosen to focus on lifestyle and routine changes as opposed to a focus on rehabilitative approaches. Finally, a qualitative approach to acquiring information was chosen to obtain individualized, client-centered experiences. 


\section{Chapter II: Literature Review}

The aim of this literature review is to synthesize the research on the current treatment of common vestibular disorders, the experiences or symptoms of people with common vestibular disorders, and lifestyle factors that are impacted by vestibular disorders. Three themes have emerged from the literature review including the current role of occupational therapy in vestibular disorders, lifestyle factors and management for vestibular disorders, and limitations in current treatment options to address lifestyle factors.

\section{Current Role of Occupational Therapy in Vestibular Disorders}

Compared to other disciplines such as physical therapy, there is a small amount of literature within occupational therapy pertaining to vestibular disorders. One significant article is American Occupational Therapy Association's purpose statement describing the role of occupational therapists providing vestibular rehabilitation including their ability to adapt the environment, adapt activities, educate on safety techniques, and address psychosocial involvement (Gronski, Neville, Kannenberg, \& Cohen, 2017). In fact, this statement is the only published standard that exists among disciplines that perform vestibular rehabilitation (Bush \& Dougherty, 2009). While this practice standard exists, there are few other studies that examine occupational therapists working with this population. There is older evidence demonstrating incorporating meaningful occupations to treatment is beneficial to motivate the patient and help symptoms decrease (Cohen, Miller, Kane-Wineland, \& Hatfield, 1995; Cohen, 1994).

\section{Lifestyle Factors and Management for Vestibular Disorders}

Many articles highlight the impact that vestibular disorders have on functional and psychosocial well-being. Dizziness, a common vestibular disorder symptom, was found to be highly correlated with mood disorders and health-related quality of life; patients with dizziness 
often restrict daily activities, avoid certain environments, and experience role limitation due to their physical problems (Cheng et al., 2012). The effect on sleep is highlighted in numerous articles including sleep position, sleep pathology associated with vestibular dysfunction, and abnormal sleep associated with vestibular vertigo (Sato, Sekine, Matsuda, \& Takeda, 2012; Besnard et al., 2018; Albathi \& Agrawal, 2017). Other lifestyle factors found to be associated with certain vestibular disorders is diet and physical activity (Schultz et al., 2015; Pollak, Kushnir, \& Goldberg, 2011). A qualitative research article found participants with vertigo reported their quality of life was impacted from factors such as emotional problems, routines, transportation, environmental factors, and social support (Mueller, Schuster, Strobl, \& Grill, 2012)

\section{Limitations in Current Treatment Options to Address Lifestyle Factors}

Treatment of vestibular disorders can vary depending on the type of vestibular disorder the person has. Vestibular rehabilitation treatment (VRT) has been found to be an effective and safe treatment for certain vestibular disorders such as unilateral peripheral vestibular impairment and vestibular migraine, however not effective for other disorders such as Ménière's disease (McDonnell \& Hillier, 2015; Vitkovic, Winoto, Rance, Dowell, \& Pain, 2013). A systematic review of vestibular rehabilitation techniques for people with unilateral vestibular hypofunction found outcomes are typically reported in patient's functional ability to ambulate or their selfperceived handicap from dizziness (Arnold, Stewart, Moor, Karl, \& Reneker, 2017). Physical repositioning maneuvers have been found to be effective in the short-term for patients with BPPV, while effective treatments for Ménière's disease are still missing (McDonnell \& Hillier 2015; Tassinari, Mandrioli, Gaggioli, \& Roberti di Sarsina, 2015). Interdisciplinary programs and incorporating other techniques to vestibular rehabilitation program have been found to be 
beneficial in improving health outcomes and quality of life (Naber et al., 2011; Menant et al., 2018). Studies specifically addressing the management of lifestyle factors are limited. 


\section{Chapter III: Project Description}

\section{Participants}

Participants will be those with common vestibular disorders including vestibular migraine, vestibular neuritis, BPPV, and Meniere's disease and will be referred to as participants or patients. These participants will be recruited at a physical therapy clinic and otoneurology clinic and selected based on a chart review by the student or recommendation from staff. The physical therapy clinic is called Rise Physical Therapy located in San Diego, California. The otoneurology clinic is located in San Diego, California. Rise Physical Therapy was chosen due to the location and because they provide vestibular rehabilitation. The otoneurology clinic was chosen because they specialize in treating vestibular disorders. A typical vestibular rehabilitation session or patient exam will last thirty minutes to one hour long likely amounting to roughly eight patients per day.

\section{Methods}

To gain information about the needs of the vestibular population, participant observation and interviews will be conducted in the physical therapy clinic and the otoneurology clinic. The treating provider will inform the patient that an occupational therapy student will be observing their session and will gain verbal consent from the patient. The student will introduce themselves, explain what occupational therapy is, briefly explain the project, and explain that there will be interview questions after the session if the patient is willing to answer them. See Appendix A for introduction script. During the therapy session or exam, the student will observe the treatments being performed and listen to what the treating provider and patient communicate to each other. Any mentioning of lifestyle factors will be mentally noted and recorded by the student at a later time in a chart located in Appendix D. After the session is over, the patient will 
be invited to be interviewed using the interview questions in Appendix B. Interviews will take place before or after sessions to not interfere with the performance or energy level of the patient during their sessions. If the patient is unable to attend the interview, the student will offer to make an appointment to interview them at another time. Interview questions will be brief in length to minimize triggering any vestibular symptoms.

Practitioners working with patients with vestibular disorders will be interviewed using interview questions in Appendix C. Practitioners may include physical therapists, occupational therapists, therapy aides or assistants, audiologists, physicians, physician assistants, psychologists, or other health care providers that work with the vestibular population. Interviews with practitioners will take place during time when the practitioner is not treating patients. The student will introduce themselves, explain the project, and an give an estimated length of time for the interview. The student will also observe weekly meetings with the team of therapists and doctors. Mentioning of lifestyle factors related to the patients with vestibular disorders during these meetings will be recorded in a chart located in Appendix D.

\section{Procedures and Timelines}

During the first four weeks of the capstone experience, the student will focus on observing patients with vestibular disorders during their sessions to familiarize themselves with vestibular concerns and treatments. The student will begin patient and staff interviews after the first two weeks and continue interviews until the end of the fourth week. Throughout the first six weeks, the student will also be assessing opportunities and barriers for the current occupational therapy role in vestibular settings. After collecting information from observations and interviews, the student will begin designing a program to address lifestyle factors for patients with vestibular concerns. This will occur during weeks six to twelve. Finally, the student will present the 
lifestyle program proposal to the site and other appropriate sites during the last week of the experience.

\section{Project Description}

The experiential component of the project spanned fourteen weeks. The original site, methods, procedures, and timeline were adjusted to best align with the intended objectives and outside factors. The first six weeks were spent solely at Rise Physical Therapy clinic. During this time, it was found that the clinic does not treat as many patients with vestibular disorders as the student had expected. However, the clinic did have a connection with an otoneurology practice in San Diego, California. The final eight weeks were spent at both Rise Physical Therapy and the otoneurology practice.

Originally, the first four weeks were intended for observation and familiarizing the student with the physical therapy clinic. Due to the minimal number of patients with vestibular disorders available, the student began interviewing and collecting information as soon as relevant patients were seen at the clinic. Instead of providing separate interviews after treatment sessions, the physical therapists preferred for the student to ask the questions to the patients during the session. During weeks three through seven, the student formally interviewed physical therapists who were identified as providing vestibular rehabilitation. All patient and staff interview answers were recorded on paper. After all patient interactions, the student took written notes on the chart located in Appendix D.

The otoneurology practice, headed by Dr. Ian Purcell, specializes in vertigo and balance disorders including vestibular disorders. Staff at this practice includes the otoneurologist, four physician assistants, and multiple medical assistants and technicians. During week seven through eight, the student familiarized themselves with the policies and procedures of this site and 
shadowed all staff. Interview of patients at this site varied depending on the patient's schedule. Upon meeting each patient, the student introduced themselves and explained their role and project. During initial evaluation appointments, the medical assistant would ask the patient questions similar to the interview questions in Appendix B. Therefore, the student would take notes on paper based on their answers. If patients were not asked these questions by staff, the student would ask the patients the interview questions in between testing and examinations as preferred by the staff. Answers were recorded on paper. After all patient interactions, the student took written notes on the chart located in Appendix D.

A few other methods were used to obtain data, information, and experience during the project. During week six, the student sent out an online survey to an online vestibular support group. The online survey questions can be found in Appendix E. The student attended a course at Rancho Los Amigos National Rehabilitation Center titled Vestibular Rehabilitation Course: Assessment and Treatment for Occupational Therapy Practitioners in week seven. Finally, the student connected with and interviewed a vestibular physical therapist in the community unrelated to the sites. Before developing the program, the student completed an online course through AOTA titled Lifestyle Redesign Series.

Program development occurred from weeks six through twelve. During weeks eight through thirteen, the student delivered short, weekly presentations about a specific vestibular diagnosis and the role of occupational therapy to staff at the otoneurology practice at the request of the staff. An example of one of the weekly presentations can be found in Appendix F. At week fourteen, the program was presented to the staff at the otoneurology practice. A sample of the program can be found in Appendix $G$ and the presentation can be found in Appendix $\mathrm{H}$. 


\section{Chapter IV: Results and Analysis}

\section{Results}

A total of 35 patients from Rise Physical Therapy clinic and the otoneurology clinic were interviewed. 31 people with vestibular disorders responded to the online survey. Seven staff members that were identified as providing treatment for patients with vestibular disorders were also interviewed. Staff included four physical therapists, two physician assistants, and one otoneurologist.

Patient interviews. Several themes emerged from patient interviews and observation of appointments. An overview of the themes can be found in Table 1. Quotes are not exact as interviews were not recorded. Quotes are estimated from student notes.

Table 1

Major Themes from Patient Interviews

Theme Example of responses

Restriction of daily activities "I no longer feel safe driving on the freeway because of my symptoms. I can no longer go places I used to be able to go easily"

"Can no longer drive and therefore can not work, cannot do normal daily activities independently at times, difficult to exercise"

"I used to work in a casino but can no longer do that because of my symptoms. Nowadays, I sit in my car for long periods of time"

"I can no longer do the activities I used to do such as running and scuba diving. During dizziness episodes I lay in bed for a couple of days" 
“Fluorescent lighting is a trigger for my symptoms. I can't stay long in places like the grocery store or Target because of it. People tell me to wear sunglasses, but that's embarrassing" "I do have to watch what I'm doing when I am having bad days such as no bending over to pick things up or reaching into the bottom of cabinets or closets."

Restriction of social interaction

Difficulty navigating and accessing healthcare

Difficulty identifying and understanding triggers
"Lost many friendships and relationships because I cannot participate and cannot travel"

"I socialize less. Socializing is very difficult because I can't hear the conversation. Struggling to hear and respond appropriately is exhausting"

"Worst.. not being able to hear the sweet voices of my grandchildren or socialize with my friends and hear sermon at church"

"I no longer really socialize as crowds are a big trigger due to sudden noise and movements."

"Everything has changed. I have had difficulty getting a diagnosis and treatment for many years now" "It took a long time to find the right doctor" "My primary care doctor told me it was vertigo and sent me home"

'I haven't seen a doctor to address my dizziness yet. I haven't been able to get an appointment yet" "I have trouble sleeping. They want me to see a special sleep doctor, but I don't want another doctor"

"I have lightheadedness and fatigue all of the time. I'm not sure what triggers it or when it started"

"I have no idea what exacerbates my symptoms" 
"Haven't sorted that out my triggers as it's been recent"

Increased stress

"I have less energy, less mental focus, anxiety which had never been an issue"

"Stress triggers my vestibular symptoms"

"Prior to the onset of my vertigo attacks, I was stressed with work"

"I had a Meniere's attack over the weekend. I believe it was triggered from the stress of my brother dying"

Restriction of daily activities. The most common theme that arose from the interviews was the restriction of daily activities. The majority of patients were found to have a change in their daily routine or activities since the onset of their vestibular disorders or symptoms. Common daily activities that patients reported to be affected by their vestibular symptoms included driving, sleeping, working, shopping, and exercising. Activities that caused a change in head position or pressure change were found to trigger symptoms in some patients and therefore the patients attempted to avoid them. Many patients revealed that they no longer drive, while some admitted to still driving but felt they were unsafe to do so. Due to symptoms or not being able to drive, many patients responded that they have taken time off of work or they no longer work. Fear of falling or falling due to vertigo was also a major theme that prevented many patients from engaging in their daily activities.

Restriction of social interaction. Another common theme from the interviews involved difficulty with or decreased social interaction. Some patients could no longer manage the sensory requirements of interacting with other people in public, while some patients felt their friends and family no longer attempted to contact them due to their disorder. Many patients responded that it 
was difficult for them to explain to their friends or family what was going on with them. Some patients felt that other people did not believe their symptoms.

Difficulty navigating and accessing healthcare. By the time patients were seen at the physical therapy clinic or otoneurology clinic, many reported seeing multiple healthcare providers prior to their current visit. Many patients described experiencing their symptoms for several months or years. Some patients felt that their concerns were not taken seriously with previous healthcare providers. A main goal for patients was to find any answers or diagnosis.

Difficulty and identifying and understanding triggers. Initial appointments and exams involved asking the patients about their symptom triggers and if anything helped their symptoms. Many patients either reported they constantly had symptoms with no known causes, while some were not sure about triggers or had not thought about it. Some patients reported that it was difficult to describe what they were feeling and expressed frustration. Many patients found the description of their symptoms and triggers to vary from how their healthcare providers describe them.

Increased stress. A common factor for the onset of symptoms was a stressful event. Multiple patients described being stressed at work or not getting enough sleep due to stress prior to a major vestibular episode. Some patients identified themselves as having anxiety and that could be a trigger for their vestibular symptoms.

Staff interviews. All staff interviewed felt that lifestyle factors impact vestibular disorders and that lifestyle factors are important to address. The staff acknowledged specific factors to address are patient dependent. Common lifestyle factors that were mentioned the most in the interviews included sleep and diet. Depending on the specific patient and their diagnosis, some of the staff recommended a gluten free diet or sodium restricted diet. All of the staff felt 
getting adequate and quality sleep will impact a patient's vestibular symptoms. A physical therapist said, "sleep after vestibular rehabilitation therapy is needed to recalibrate and integrate the information in the brain." A physician's assistant explained that lifestyle changes can be beneficial, however "the patient actually needs to make those lifestyle changes and needs to do it consistently for it to make a difference, patients have a difficult time adhering to change." Another physician's assistant explained "some patients don't want to take medications, so we need to go at the problem from all angles." A physical therapist revealed he does provide lifestyle interventions, however he noted "the lifestyle changes I recommend to patients are not typical of a general physical therapist's intervention."

Observation. Observation of patient appointments and exams revealed the extent to which lifestyle factors and interventions were provided or talked about between the provider and the patient. The majority of lifestyle factors mentioned during physical therapy sessions were physical activity and sleep. The majority of lifestyle factors mentioned during otoneurology exams were sleep and diet. The providers at the otoneurology clinic did recommend some of their vestibular patients to purchase a migraine diet book. For patients with vestibular neuritis, the providers touched upon the importance of reducing their viral load by following healthy habits such as eating healthy, exercising, and sleeping. 


\section{Chapter V: Discussion}

The objectives of this capstone project were to identify lifestyle factors that impact and support vestibular disorders, develop and propose a lifestyle modification program, assess opportunities and barriers for OT role in vestibular settings, and advocate for OT role in this setting.

\section{Lifestyle Factors}

Interview responses and observation results confirmed that lifestyle factors impact and have the potential to support people with vestibular disorders. The unpredictability, severity, and variability of vestibular symptoms can affect a person physically, cognitively, and emotionally. Participant responses support previous research showing that vestibular symptoms can lead to restriction of daily activities, avoidance of certain environments, social isolation, and role limitations (Cheng et al., 2012; Harun, Li, Bridges, \& Agrawal, 2016). Responses also support the evidence that there is a high prevalence of anxiety in people with inner ear disorders (Best, Eckhardt-Henn, Tschan, \& Dieterich, 2009). One factor that was rarely mentioned was leisure, most likely due to individuals wanting to attend to the factors that are perceived to be more important such as working or self-care.

\section{Program Development}

Occupational therapists are equipped with the knowledge to provide services for individuals with vestibular disorders. An occupation-based program focusing on lifestyle management and modification was developed during the last half of the experiential component. A sample of the program can be found in Appendix G. The program consists of goal setting, reflection, and five customizable modules: vestibular symptom management, self-care and routines, health management and advocacy, activities of daily living, and community integration. 
The goals of these modules include bringing awareness to activity patterns, analyzing activity patterns and personal risk factors, changing habits and routines, and developing a customizable, personal plan.

\section{Opportunities for Occupational Therapy Role}

The findings of this project supported the need for an expanded role for occupational therapy working with the population. Occupational therapists are equipped to perform vestibular rehabilitation treatment. However, this type of intervention relies heavily on exercises and oftentimes is associated with physical therapy. Occupational therapists are uniquely capable of providing lifestyle modifications that could benefit this population. Occupational therapy has shown benefits in providing lifestyle modifications in populations with other chronic disease such as diabetes and chronic pain (Pyatak et al., 2019; Simon \& Collins, 2017). Occupational therapists may have an opportunity to provide a lifestyle modification intervention in a primary care setting as vestibular vertigo is frequently seen in primary care settings (Neuhauser et al., 2008). Another area occupational therapists have a unique opportunity in providing care for this population is in fall prevention. Finally, an occupational therapy role in treating this population can be in the assessment and treatment of vestibular dysfunction in patients already being seen with stroke, traumatic brain injury, multiple sclerosis, ototoxicity, and other disorders that can affect the vestibular system.

\section{Barriers for Occupational Therapy Role}

The findings of this project also highlighted barriers for the role of occupational therapy in providing lifestyle management for the vestibular population. While occupational therapists are educated in providing vestibular rehabilitation and intervention for treating patients with vestibular disorders, there are barriers in getting continuing education once one graduates. Most 
vestibular continuing education courses are tailored toward physical therapists. Another barrier is the availability of settings for occupational therapists to provide intervention for patients with vestibular disorders. Typically, patients with vestibular disorders are living in the community and are not seeking care in a hospital or outpatient therapy setting where many occupational therapists work. Patients with vestibular disorders are seeking care with their primary care physician, a specialist physician, or physical therapist. Another barrier includes the lack of understanding of occupational therapy's role from patient and staff working with this population. For example, when speaking with various healthcare providers about the role of occupational therapy, many providers thought that occupational therapists focused on hands injuries or workrelated difficulties. 


\section{Chapter VI: Conclusion}

\section{Limitations}

Throughout the capstone experience, various limitations became apparent. Limitations included time, setting, and environmental factors. The first limitation was the availability of patients. Although the physical therapy clinic provided vestibular rehabilitation, the actual number of patients with vestibular disorders was low. Many patients with these disorders would cancel their appointments. At the otoneurology clinic, the number of patients with vestibular disorders was much higher, however there were still some limitations. For example, most patients did not have a specific diagnosis yet as they were in the beginning stages of their care. This could have affected the individual's daily routine as they were not receiving specific treatment for anything yet. Also, some patients had comorbid conditions such as diabetes that could affect their lifestyle factors. Due to the time constraints of the project, no long-term follow-up with individuals was feasible. Finally, the findings from the interviews and observation cannot be generalized as individuals were seeking care in a highly specialized clinic. Implications for OT

The findings of this capstone experience have the following implications for occupational therapy practice:

- Occupational therapy has a unique role within an interdisciplinary team in providing lifestyle modification intervention for patients with vestibular disorders and concerns.

- Opportunities for occupational therapists working with this population include providing vestibular rehabilitation, providing lifestyle modification and management intervention, and providing interventions for vestibular concerns in individuals with other comorbid conditions. 
- Barriers for occupational therapists working with this population include lack of research, lack of continuing education, decreased access to patient, and lack of understanding of OT role from other staff.

\section{Conclusion}

In the United States, approximately six in ten adults have a chronic disease (National Center for Chronic Disease Prevention and Health Promotion, 2019). Like other chronic diseases, vestibular disorders have considerable impact on the affected person's health and wellbeing (Agrawal, Ward, \& Minor, 2013). The findings from this capstone project support previous research on the impact vestibular disorders have on daily life and the increased role for occupational therapy in providing lifestyle-based intervention for the vestibular population. Occupational therapy can provide a unique contribution to the interdisciplinary healthcare team when working with individuals with vestibular disorders. 


\section{References}

Agrawal, Y., Carey, J. P., Della Santina, C. C., Schubert, M. C., \& Minor, L. B. (2009). Disorders of balance and vestibular function in US adults: Data from the national health and nutrition examination survey, 2001-2004. Archives of Internal Medicine, 169(10), 938. https://doi.org/10.1001/archinternmed.2009.66

Agrawal, Y., Ward, B., \& Minor, L. (2013). Vestibular dysfunction: Prevalence, impact and need for targeted treatment. Journal of Vestibular Research, (3), 113-117. $\underline{\text { https://doi.org/10.3233/VES-130498 }}$

Albathi, M., \& Agrawal, Y. (2017). Vestibular vertigo is associated with abnormal sleep duration. Journal of Vestibular Research, 27(2-3), 127-135. https://doi.org/10.3233/VES-170617

American Physical Therapy Association. (2019). The physical therapist scope of practice. Retrieved from https://www.apta.org/ScopeOfPractice/

Arnold, S. A., Stewart, A. M., Moor, H. M., Karl, R. C., \& Reneker, J. C. (2017). The effectiveness of vestibular rehabilitation interventions in treating unilateral peripheral vestibular disorders: A systematic review. Physiotherapy Research International, 22(3), 1-15. https://doi.org/10.1002/pri.1635

Bagwell, D. K. (2018). Quality of life. Salem Press Encyclopedia of Health. Retrieved from http://search.ebscohost.com/login.aspx ?direct=true\&db=ers\&AN=93872189\&site=edslive

Besnard, S., Tighilet, B., Chabbert, C., Hitier, M., Toulouse, J., Le Gall, A., ... Smith, P. F. (2018). The balance of sleep: Role of the vestibular sensory system. Sleep Medicine Reviews, 42, 220-228. https://doi.org/10.1016/j.smrv.2018.09.001 
Bhattacharyya, N., Gubbels, S. P., Schwartz, S. R., Edlow, J. A., El-Kashlan, H., Fife, T., ... Corrigan, M. D. (2017). Clinical practice guideline: Benign paroxysmal positional vertigo (Update). Otolaryngology-Head and Neck Surgery, 156(3_suppl), S1-S47. https://doi.org/10.1177/0194599816689667

Bigelow, R. T., Semenov, Y. R., du Lac, S., Hoffman, H. J., \& Agrawal, Y. (2016). Vestibular vertigo and comorbid cognitive and psychiatric impairment: The 2008 National Health Interview Survey. Journal of Neurology, Neurosurgery \& Psychiatry, 87(4), 367-372. https://doi.org/10.1136/jnnp-2015-310319

Boyer, F. C., Percebois-Macadré, L., Regrain, E., Lévêque, M., Taïar, R., Seidermann, L., ... Chays, A. (2008). Vestibular rehabilitation therapy. Neurophysiologie Clinique/Clinical Neurophysiology, 38(6), 479-487. https://doi.org/10.1016/j.neucli.2008.09.011

Bush, M., \& Dougherty, W. (2015). Assessment of vestibular rehabilitation therapy training and practice patterns. Journal of Community Health, 40(4), 802-807. https://doi.org/10.1007/s10900-015-0003-7

Cheng, Y.-Y., Kuo, C.-H., Hsieh, W.-L., Lee, S.-D., Lee, W.-J., Chen, L.-K., \& Kao, C.-L. (2012). Anxiety, depression and quality of life (QoL) in patients with chronic dizziness. Archives of Gerontology and Geriatrics, 54(1), 131-135. https://doi.org/10.1016/j.archger.2011.04.007

Clark, F. A. (2015). Lifestyle redesign: the intervention tested in the USC well elderly studies (2nd edition). Bethesda, MD: AOTA Press, The American Occupational Therapy Association, Inc. 
Cohen, H. S. (2014). Use of the vestibular disorders activities of daily living scale to describe functional limitations in patients with vestibular disorders. Journal of Vestibular Research, 24(1), 33-38. https://doi.org/10.3233/VES-130475

Cohen, H. S., Kim, G. R., Graziano, M., Malmstrom, E., \& Sharpe, M.H. (2009). International survey of vestibular rehabilitation therapists by the Barany Society ad hoc committee on vestibular rehabilitation therapy. Journal of Vestibular Research, (1,2), 15-20. https://doi.org/10.3233/VES-2009-0339

Cohen, H. S, Miller, L.V., Kane-Wineland, M., \& Hatfield, C.L. (1995). Case report. Vestibular rehabilitation with graded occupations. American Journal of Occupational Therapy, 49(4), 362-367.

Cole, M., \& Tufano, R. (2008). Applied theories in occupational therapy (1st ed.). Thorofare, NJ.: Slack.

DynaMed Plus. (2018). Vestibular neuronitis. Ipswich, MA: EBSCO Information Services. Retrieved from http://www.dynamed.com.prxusa.lirn.net/topics/dmp AN T909391\#References

Farhud D. D. (2015). Impact of lifestyle on health. Iranian journal of public health, 44(11), $1442-1444$.

Gronski, M., Neville, M., Kannenberg, K., \& Cohen, H. (2017). Vestibular impairment, vestibular rehabilitation, and occupational performance. American Journal of Occupational Therapy, 71, 1-13.

Goddard, J. C., \& Fayad, J. N. (2011). Vestibular neuritis. Otolaryngologic Clinics of North America, 44(2), 361-365. https://doi.org/10.1016/j.otc.2011.01.007 
Harun, A., Li, C., Bridges, J. F., \& Agrawal, Y. (2016). Understanding the experience of agerelated vestibular loss in older individuals: A qualitative study. Patient, 9(4), 303-309. doi:10.1007/s40271-015-0156-6

Hoffer, M. E., Balaban, C. D., \& Cohen, H. S. (2011). Assessment of functional outcomes in patients with vestibular disorders after rehabilitation. NeuroRehabilitation, 29(2), 173178.

Honaker, J. A., \& Kretschmer, L. W. (2014). Impact of fear of falling for patients and caregivers: Perceptions before and after participation in vestibular and balance rehabilitation therapy. American Journal of Audiology, 23(1), 20-33. https://doi.org/10.1044/1059-0889(2013/12-0074)

Hilton, D.B. \& Shermetaro, C., (2019). Migraine-associated vertigo (Vestibular migraine). In StatPearls [Internet]. Retrieved from https://www-ncbi-nlm-nih-gov.prxusa.lirn.net/books/NBK507859/

Kielhofner, G., \& Burke, J. P. (1980). A Model of Human Occupation, part 1. Conceptual framework and content. American Journal of Occupational Therapy, 34(9), 572-581. https://doi.org/10.5014/ajot.34.9.572

Killington, M. J., Speck, K., Kahlbaum, J., Fabian, J., Edwards, D., \& Stobie, J. (2015). Qualityof-life for individuals with a vestibular impairment following an acquired brain injury (ABI); the clients' perspective. Brain Injury, 29(4), 490-500. https://doi.org/10.3109/02699052.2014.995226

Koenen, L. \& Andaloro, C. (2019). Meniere disease. In StatPearls [Internet]. Retrieved from https://www-ncbi-nlm-nih-gov.prx-usa.lirn.net/books/NBK536955/ 
McDonnell, M. N., \& Hillier, S. L. (2015). Vestibular rehabilitation for unilateral peripheral vestibular dysfunction. The Cochrane Library. John Wiley \& Sons, Ltd. https://doi.org/10.1002/14651858.CD005397.pub4

Menant, J. C., Migliaccio, A. A., Sturnieks, D. L., Hicks, C., Lo, J., Ratanapongleka, M., ... Lord, S. R. (2018). Reducing the burden of dizziness in middle-aged and older people: A multifactorial, tailored, single-blind randomized controlled trial. PLOS Medicine, 15(7), e1002620. https://doi.org/10.1371/journal.pmed.1002620

Mueller, M., Schuster, E., Strobl, R., \& Grill, E. (2012). Identification of aspects of functioning, disability and health relevant to patients experiencing vertigo: a qualitative study using the international classification of functioning, disability and health. Health and Quality of Life Outcomes, 10(1), 75. https://doi.org/10.1186/1477-7525-10-75

Murdin, L., \& Schilder, A. G. M. (2015). Epidemiology of balance symptoms and disorders in the community: A systematic review. Otology \& Neurotology, 36(3), 387-392. https://doi.org/10.1097/MA0.0000000000000691

Naber, C. M., Water-Schmeder, O., Bohrer, P. S., Matonak, K., Bernstein, A. L., \& Merchant, M. A. (2011). Interdisciplinary treatment for vestibular dysfunction: The effectiveness of mindfulness, cognitive-behavioral techniques, and vestibular rehabilitation. Otolaryngology-Head and Neck Surgery, 145(1), 117-124. https://doi.org/10.1177/0194599811399371

National Center for Chronic Disease Prevention and Health Promotion. (2019). About chronic diseases. Retrieved from https://www.cdc.gov/chronicdisease/about/index.htm 
Neuhauser, H. K., Radtke, A., von Brevern, M., Lezius, F., Feldmann, M., \& Lempert, T. (2008). Burden of dizziness and vertigo in the community. Archives of Internal Medicine, 168(19), 2118. https://doi.org/10.1001/archinte.168.19.2118

Pollak, L., Kushnir, M., \& Goldberg, H. S. (2011). Physical inactivity as a contributing factor for onset of idiopathic benign paroxysmal positional vertigo. Acta Oto-Laryngologica, 131(6), 624-627. https://doi.org/10.3109/00016489.2011.552524

Pyatak, E., King, M., Vigen, C. L. P., Salazar, E., Diaz, J., Schepens Niemiec, S. L., ... Shukla, J. (2019). Addressing diabetes in primary care: Hybrid effectiveness-implementation study of Lifestyle Redesign ${ }^{\circledR}$ occupational therapy. American Journal of Occupational Therapy, 73(5), 7305185020p1. https://doi.org/10.5014/ajot.2019.037317

Sato, G., Sekine, K., Matsuda, K., \& Takeda, N. (2012). Effects of sleep position on time course in remission of positional vertigo in patients with benign paroxysmal positional vertigo. Acta Oto-Laryngologica, 132(6), 614-617. https://doi-org.prxusa.lirn.net/10.3109/00016489.2012.655860

Schultz, A., Neves-Souza, R., Costa, V., Meneses-Barriviera, C., Franco, P., \& Marchiori, L. (2015). Is there a possible association between dietary habits and benign paroxysmal positional vertigo in the elderly? The importance of diet and counseling. International Archives of Otorhinolaryngology, 19(04), 293-297. https://doi.org/10.1055/s-00351551551

Simon, A. U., \& Collins, C. E. R. (2017). Lifestyle Redesign ${ }^{\circledR}$ for chronic pain management: A retrospective clinical efficacy study. American Journal of Occupational Therapy, 71(4), 1-7. https://doi-org.prx-usa.lirn.net/10.5014/ajot.2017.025502 
Tassinari, M., Mandrioli, D., Gaggioli, N., \& Roberti di Sarsina, P. (2015). Meniere's disease treatment: A patient-centered systematic review. Audiology and Neurotology, 20(3), 153-165. https://doi.org/10.1159/000375393

Vestibular Disorders Association. (2016). The human balance system: A complex coordination of central and peripheral systems. Retrieved from https://vestibular.org/sites/default/files/page_files/Documents/Human\%20Balance\%20Sy stem_36.pdf

Vestibular Disorders Association. (2018). Vestibular disorders: An overview. Retrieved from https://vestibular.org/sites/default/files/page_files/Documents/Vestibular\%20Disorders\% 20an\%20Overview_77.pdf

Vitkovic, J., Winoto, A., Rance, G., Dowell, R., \& Paine, M. (2013). Vestibular rehabilitation outcomes in patients with and without vestibular migraine. Journal of Neurology, 260(12), 3039-3048. https://doi.org/10.1007/s00415-013-7116-7 
APPENDIX A

Student Introduction Script 


\section{Appendix A}

“Hi, my name is Michelle. I'm an occupational therapy student. I'm completing my doctoral project focusing on lifestyle factors related to vestibular disorders. I'll be observing your session today and if you are willing, I would like to ask you a few questions after your session is over. The questions will be about your vestibular symptoms and how it impacts your daily life. It should take less than 10 minutes." 


\section{APPENDIX B}

Participant Interview Questions 


\section{Appendix B}

1. Has your daily routine or activities changed since you have experienced vestibular symptoms?

2. What daily activities trigger your vestibular symptoms?

3. What environments trigger vestibular symptoms for you?

4. Is there anything that helps decrease your vestibular symptoms? 
APPENDIX C

Interview Questions for Practitioners 


\section{Appendix C}

1. Where do you identify future needs in this area of practice?

2. What are your thoughts on lifestyle changes (for example, diet, exercise, sleep routine, etc) on the impact of vestibular disorders?

3. Do you ever provide interventions or advice in regard to lifestyle changes?

4. If so, are those lifestyle changes followed?

5. Do you feel like there are common barriers to patients implementing lifestyle changes? 


\section{APPENDIX D}

Lifestyle Factors Chart 


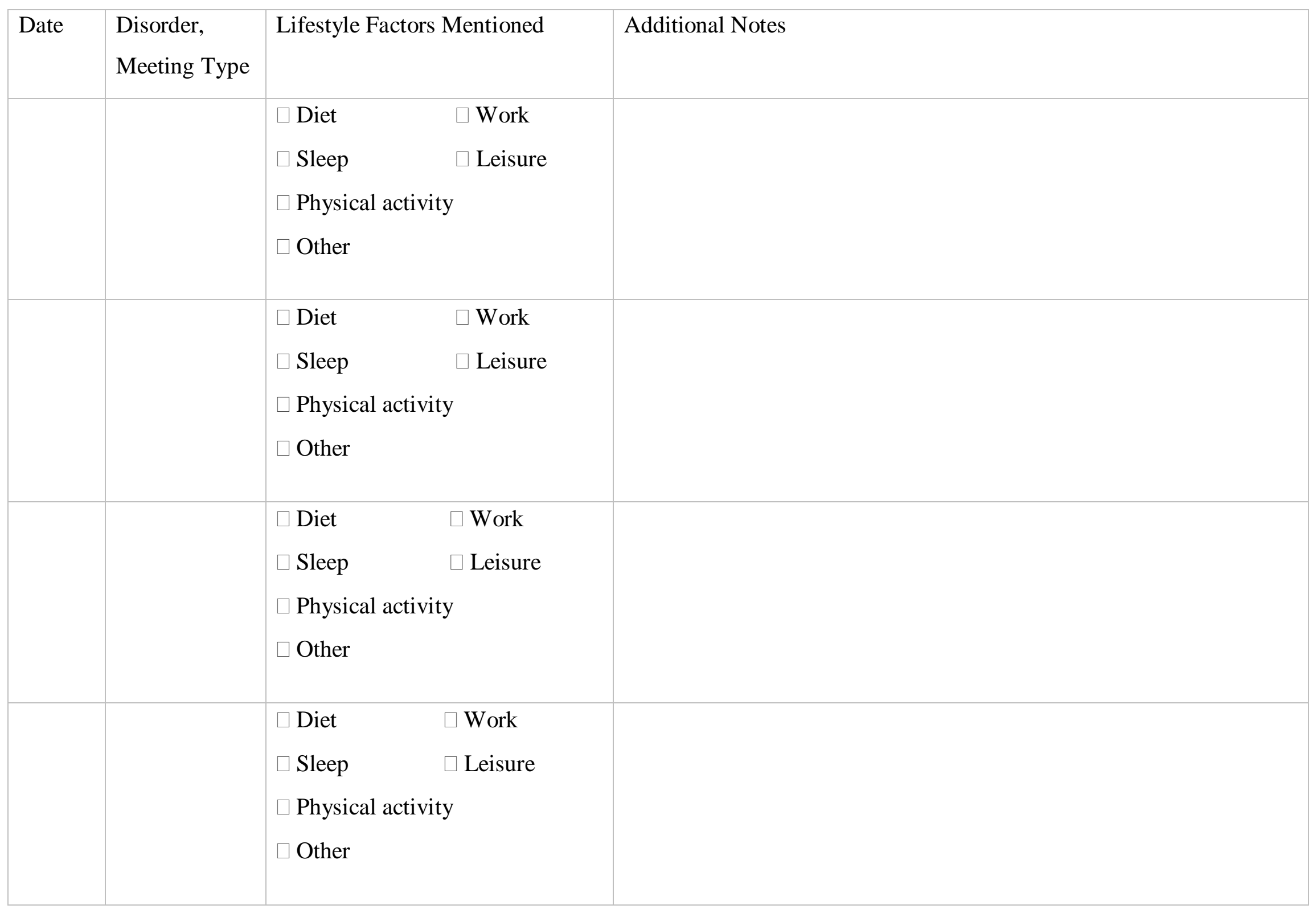


APPENDIX E

\section{Online Survey}


Appendix E

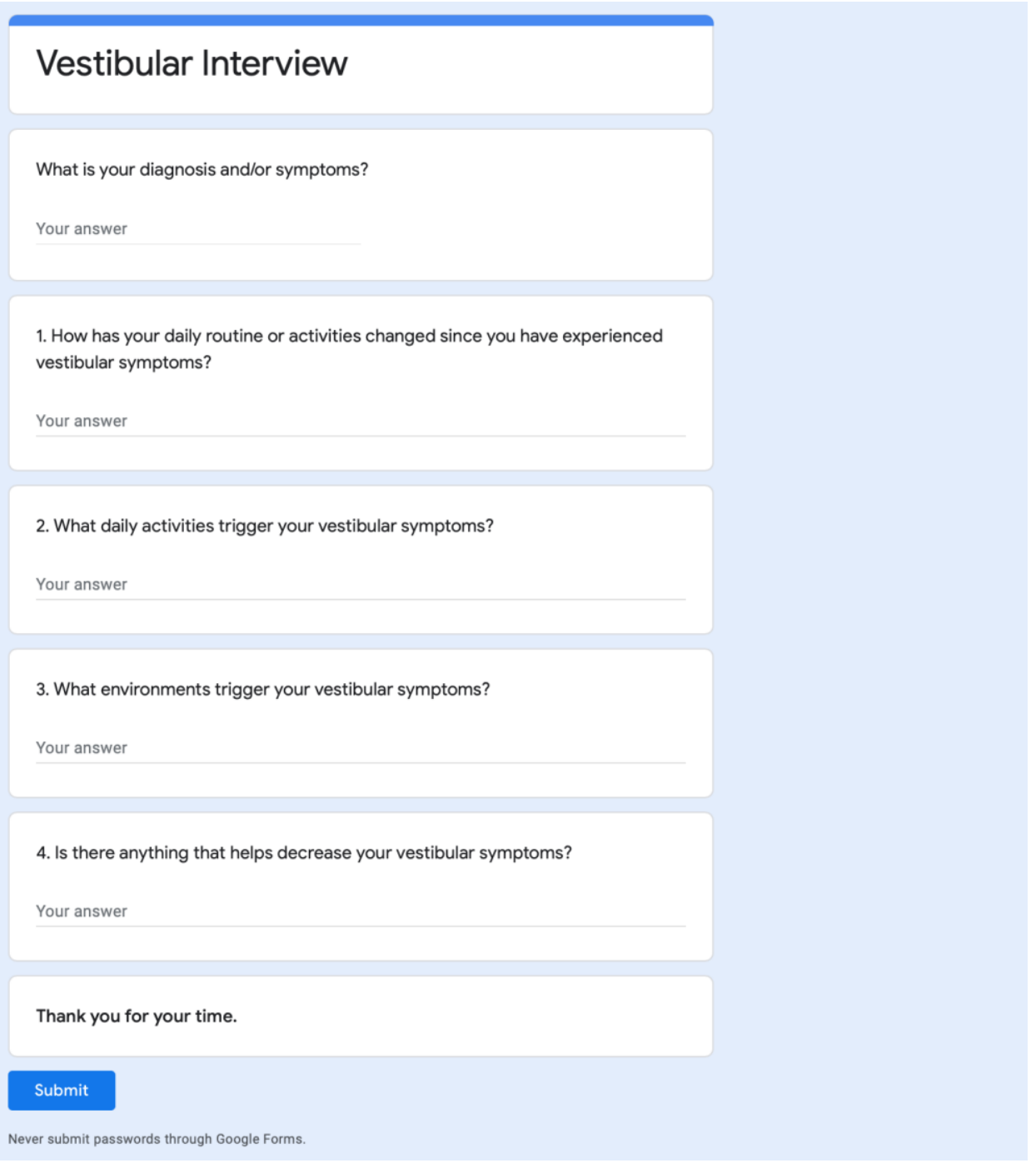


APPENDIX F

Weekly Presentation Example 
Diagnosis: Superior semicircular canal dehiscence

\section{Appendix F}

- Opening in bone overlying the superior semicircular canal

\section{Etiology}

- Developmental abnormality

- No known cause for erosion of the bone

- Trauma may play a role- head trauma, major pressure altering event

\section{Epidemiology}

- About $2 \%$ of population has thinning bone that may lead to SCD

- Unknown prevalence, possibly .1\%

\section{Symptoms}

- Pressure sensitivity

- Pressure induced vertigo

- Some people get worse with coughing, straining, sneezing, etc

- Auditory

Tullio's phenomenon (sound induced vertigo)
- Autophony
○ Tinnitus
- Fullness
- Hearing loss

\section{Diagnosis}

- Oscillopsia

- Temporal bone CT scan

- Valsalva test

- Fistula test

- VEMPs

- Audiometry

- ENG

\section{Treatment}

- Conservative approach- avoiding lifting, straining, bending over, popping ears, forceful nose blowing, air pressure changes, high speed elevators, scuba diving, loud noises

- $\quad$ Surgical treatment

$\circ \quad$ Plugging and capping

- Resurfacing

\section{Role of occupational therapy}

- Adapting or modifying activities to avoid pressure changes (ex. dressing)

- Recommending adaptive equipment and home modifications to improve safety and avoid symptom provoking activities

$\circ$ Ex. relocation of items in environment

- Auditory management

- CBT, mindfulness, psychoeducation

- Sound therapy- using external noise to counteract perception and reaction (distraction)

- Role in providing education about hearing protection, safe noise thresholds, auditory health 


\section{APPENDIX G}

Lifestyle Management Program for People with Vestibular Disorders Sample 
Table of Contents

Introduction

$\begin{array}{lc}\text { Personal Plan and Goal Setting } & 8\end{array}$

Module 1: Vestibular Symptom Management / Self-Management 13

1.1 Discussion 13

Baseline 13

Emergency Planning 13

1.2 Goals 13

1.3 Suggested Discussion Questions 14

1.4 Suggested Activities $\quad 14$

Activity: Symptom Log 14

Activity: Developing a "Vestibular Action Plan" (VAP) 15

$\begin{array}{ll}1.5 \text { Handouts } & 15\end{array}$

Handout 1.A. Symptom Tracker 16

$\begin{array}{ll}\text { Handout 1.B. My Vestibular Action Plan } & 18 \\ 1.6 \text { Resources } & 15\end{array}$

Module 2: Self-Care and Routines 23

2.1 Discussion 23

Stress Management 23

Sleep Routine $\quad 23$

Eating Routine $\quad 24$

Physical Activity 24

2.2. Goals 25

2.3 Suggested Discussion Questions $\quad 25$

2.4 Suggested Activities 26

Activity: Tai chi 26

Activity: Practice breathing techniques $\quad 27$

Activity: Practice relaxation techniques 27

Activity: Creating a Balanced Sleep Routine 27

Activity: Balanced Food Log $\quad 27$

Activity: Sodium Handout 27

Activity: Weekly Water Intake Tracker 28

2.5 Handouts 28

Handout 2.A. Tai Chi Handout 31

Handout 2.B. Breathing Techniques Handout 33

Handout 2.C. Relaxation Techniques Handout 34

Handout 2.D. Sleep Routine Handout 35

Handout 2.E. Sleep Hygiene Tips Handout 36

Handout 2.F. Balanced Food Log Handout 37

Handout 2.G. Sodium Handout 38

Handout 2.H. Hydration Handout 39

Handout 2.I. Weekly Water Intake Tracker 41

2.6 Resources 
$\begin{array}{ll}\text { References } & 29\end{array}$

Module 3: Health Management and Advocacy 42

3.1 Discussion 42

Navigating and Accessing Healthcare 42

Medication Management 42

3.2 Goals $\quad 43$

3.3 Suggested Discussion Questions 43

3.4 Suggested Activities $\quad 44$

Activity: Vestibular medical terminology 44

Activity: Role Play a Doctor Appointment 44

Activity: Fill out medication log 44

3.5 Handouts 44

Handout 3.A. Vestibular Medical Terminology Handout $\quad 46$

Handout 3.B. My Medication Log Handout 47

3.6 Resources $\quad 44$

Module 4: Activities of Daily Living $\quad 48$

4.1 Discussion 48

Home Management and Fall Prevention 48

$\begin{array}{ll}4.2 \text { Goals } & 48\end{array}$

4.3 Suggested Discussion Questions 48

4.4 Suggested Activities $\quad 49$

Activity: Home Safety Self-Evaluation $\quad 49$

Activity: Adaptive Equipment 49

Activity: Fall Self Reflection and Prevention Tips 49

Activity: Rehearse safe body mechanic and energy conservation techniques 49

4.5 Handouts 49

Handout 4.A. Home Safety Self-Evaluation $\quad 50$

Handout 4.B. Home Safety Tips 52

Handout 4.C. Adaptive Equipment Handout 53

Handout 4.D. Fall Self Reflection Handout $\quad 55$

Handout 4.E. Fall Prevention Tips 56

4.6 Resources 49

Module 5: Community Integration and Work 57

5.1 Discussion 57

Transportation $\quad 57$

Social Interaction $\quad 57$

Work $\quad 58$

5.2. Goals 58

5.3 Suggested Discussion Questions 58

5.4 Suggested Activities $\quad 59$

Activity: Creating a Transportation Resource List 59

Activity: Find a vestibular support group $\quad 59$ 
Activity: Workplace Accommodations

Activity: Role play speaking with boss or manager about workplace adjustments and accommodations

5.5 Handouts

Handout 5.A. Transportation Resources Handout

61

Handout 5.B. Workplace Accommodation Handout

63

5.6 Resources

60

References

60

\section{Reflection}

64

Suggested Discussion Questions

64

Suggested Activities

Activity: My Balanced Day

64

Activity: Reasons to Celebrate

64

Activity: Continuation of Goals

64

Handouts

64

Handout 6.A. My Balanced Day

65

Handout 6.B. Reasons to Celebrate

66 


\section{Introduction}

The Lifestyle Management Program for Individuals with Vestibular Disorders is divided into five modules with various topics intended to be covered in individual sessions. There is a preliminary session to develop goals and a reflection session to end the program. The specific modules and topics will be selected by the individual according to the individual's needs and goals. The therapist should evaluate each individual's ability to engage in the modules. Modules and topics can be modified as needed. Individuals should obtain medical clearance before participating. The modules along with their topics include:

\begin{tabular}{|c|c|}
\hline Module & Topic \\
\hline $\begin{array}{l}\text { 1. Vestibular Symptom } \\
\text { Management/Self-Management }\end{array}$ & $\begin{array}{l}\text { - } \text { Baseline } \\
\text { - Emergency Planning }\end{array}$ \\
\hline 2. Self-Care and Routines & $\begin{array}{l}\text { - } \text { Stress Management } \\
\text { - Sleep Routine } \\
\text { - Eating Routine } \\
\text { - } \quad \text { Physical Activity }\end{array}$ \\
\hline 3. Health Management and Advocacy & $\begin{array}{l}\text { - Navigating and Accessing } \\
\text { Healthcare } \\
\text { - Medication Management }\end{array}$ \\
\hline 4. Activities of Daily Living & $\begin{array}{l}\text { - Home Management and Fall } \\
\text { Prevention }\end{array}$ \\
\hline 5. Community Integration & $\begin{array}{ll}\text { - } & \text { Transportation } \\
\text { - Social Interaction } \\
\text { - Work }\end{array}$ \\
\hline
\end{tabular}


The modules and topics are suggestions and new topics may emerge based on the individual's needs. It is suggested for one topic to be completed each week. The goals of the modules include bringing awareness to activity patterns, analyzing activity patterns and personal risk factors, changing habits and routines, and developing of a customizable, personal plan.

Within each module there will be a discussion of topics, goals, suggested discussion questions, suggested activities, handouts, and resources. The handouts can be modified as necessary for the specific needs of the individual. The occupational therapist can pick and choose which activities to integrate throughout the session.

\section{Target Population}

The target population for this program includes individuals who have a diagnosed vestibular disorder and have a willingness to make lifestyle changes. The diagnoses may include but are not limited to vestibular neuritis or labyrinthitis, vestibular migraine, vestibular hypofunction, Ménière's disease, secondary endolymphatic hydrops, perilymph fistula, and superior canal dehiscence. Individuals with known vestibular dysfunction and no clear diagnosis may also benefit from this program. Individuals with benign paroxysmal positional vertigo (BPPV) may not be indicated for this program because treatment by canalith repositioning maneuvers from an experienced healthcare provider are recommended. If done correctly, this treatment should provide relief from symptoms and therefore lifestyle modifications may not be necessary. However, individuals with chronic BPPV may be considered.

\section{Facilitators}


This program is intended to be facilitated by occupational therapists. It is recommended for occupational therapists to take continuing education in the area of vestibular disorders due to the nature and complexity of this population. Occupational therapy assistants (COTAs) with experience working with this population and students may also be appropriate facilitators of this program under the appropriate supervision of an occupational therapist.

\section{Closure}

At termination of the program, content will be reviewed, individuals will have all handouts, and will have opportunity to reflect on learning and accomplishments. 


\section{Personal Plan and Goal Setting}

The initial session will include a review of the individual's occupational profile, typical day, and personal goals. The information for the occupational profile can obtained through formal interview or conversation. The AOTA Occupational Profile Template may be used from https://www.aota.org/ /media/Corporate/Files/Practice/Manage/Documentation/AOTAOccupational-Profile-Template.pdf

The therapist should work with the client to fill out their typical day, their strengths and weaknesses, and establish personal goals. 


\section{Occupational profile:}




\section{My Typical Day}

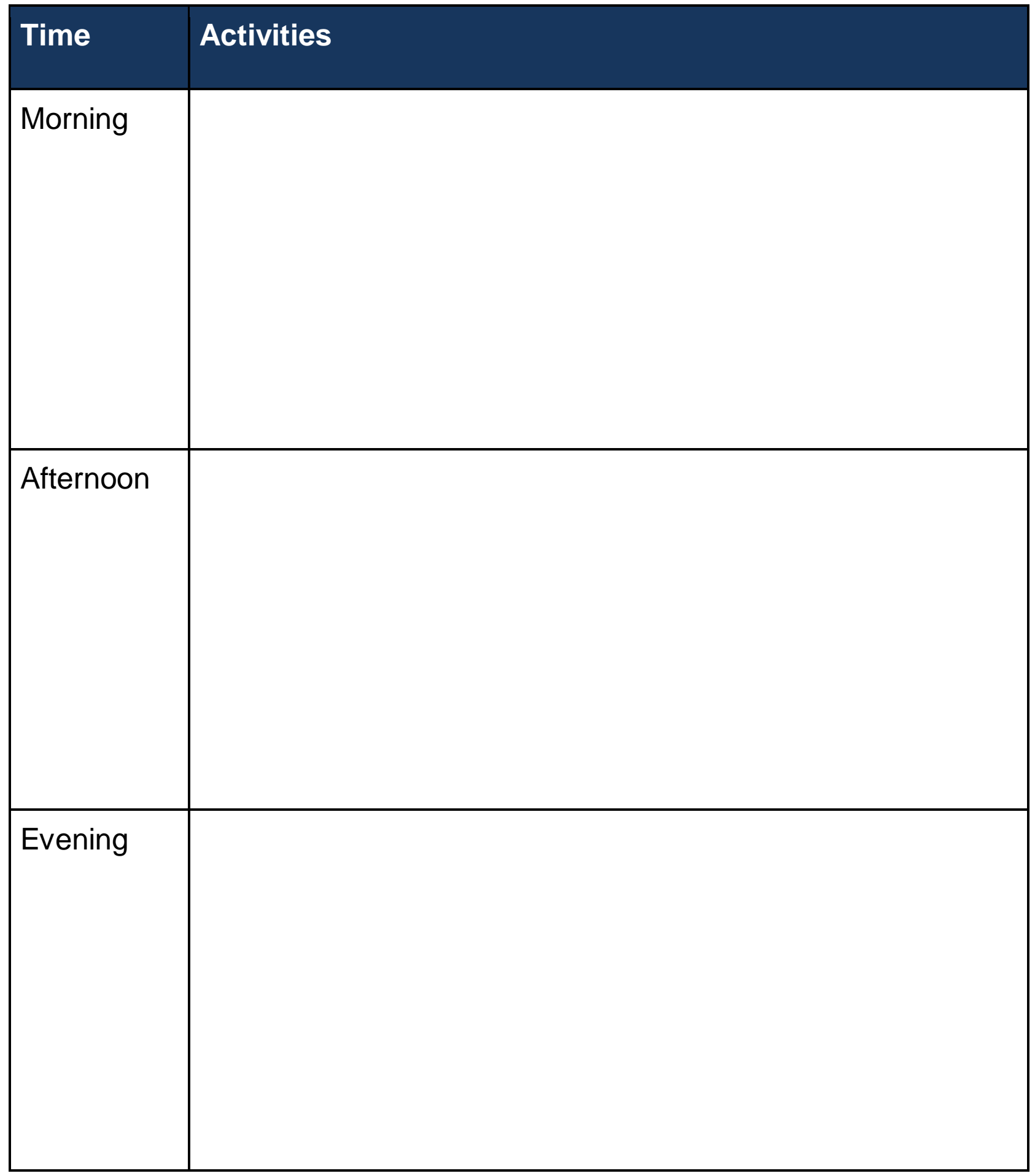


Directions: Use the space below to list personal strengths and weaknesses to living a health-promoting life. List any outside supports and barriers to staying healthy.

\section{Personal Strengths \\ Personal Weaknesses}


Directions: Come up with at least 3 specific, measurable, and realistic goals for each box. Include a time frame for these goals.

My short-term goals:

My long-term goals: 


\section{Module 1: Vestibular Symptom Management / Self-Management}

\subsection{Discussion}

\section{Baseline}

Individuals with vestibular disorders can experience a variety of symptoms in different ways. Typically, the symptoms such as vertigo are not visible to the outside eye. Oftentimes it can be difficult for people to describe and remember symptoms. However, the understanding and documentation of symptoms are important for diagnosis, treatment, and knowledge for the person to live well with their disorder. There are different types of vestibular disorders including BPPV, vestibular neuritis, Ménière's disease, vestibular migraine, and perilymph fistula. Many individuals experiencing vestibular symptoms may not have a clear diagnosis yet.

\section{Emergency Planning}

Due to the nature of vestibular symptoms, it can be difficult to discern when one should stay home and rest or if something more serious is going on. Describing what is happening to a person with vestibular disorders can be difficult especially during an acute attack or emergency situation. It is important to be prepared for a crisis situation if one were to arise. Communicating in advance about the person's triggers, treatments, and emergency plans can give peace of mind to the person, their friends and family, and healthcare team.

\subsection{Goals}

- Identify the current roles, habits, values, daily routines, activity tolerance, symptom triggers, and current stage of change and acceptance of the individual. 
- To develop a communication tool between the doctor, the person with vestibular disorder, and other health care providers

\subsection{Suggested Discussion Questions}

- Baseline

- What is your daily routine?

- What do you do? What are your major responsibilities?

- How would you describe your vestibular symptoms?

- How do your vestibular symptoms impact your day to day activities?

- Do you currently record your symptoms in any way?

- Emergency Planning

- Do you have an emergency plan in place?

- How do you manage an acute attack?

- What do you currently do to prevent your vestibular symptoms?

\subsection{Suggested Activities}

\section{Activity: Symptom Log}

- Have the individual fill out symptom log for approximately 2-3 weeks or longer using handout 1.A. The individual can use the symptom box to help them describe symptoms. The individual can use alternatives to a paper log such as phone apps. A log of symptoms can help the individual and their health care team identify triggers. The individual and their health care team can use this information to help with diagnosis, treatment, and promote engagement in daily activities to lessen severity of symptoms or avoid symptom provoking triggers. 


\section{Activity: Developing a "Vestibular Action Plan" (VAP)}

- Work together with individual to fill out handout 1.B. to develop a home plan and an emergency plan.

\subsection{Handouts}

- Handout 1.A. Symptom Tracker

- Handout 1.B. My Vestibular Action Plan

\subsection{Resources}

\begin{tabular}{|l|l|}
\hline VeDA Understanding Your Symptoms & $\begin{array}{l}\text { https://vestibular.org/understanding- } \\
\text { vestibular-disorder/symptoms }\end{array}$ \\
\hline Isabel Symptom Checker & https://symptomchecker.isabelhealthcare.com \\
\hline
\end{tabular}


1.A. Daily Symptom Tracker Handout

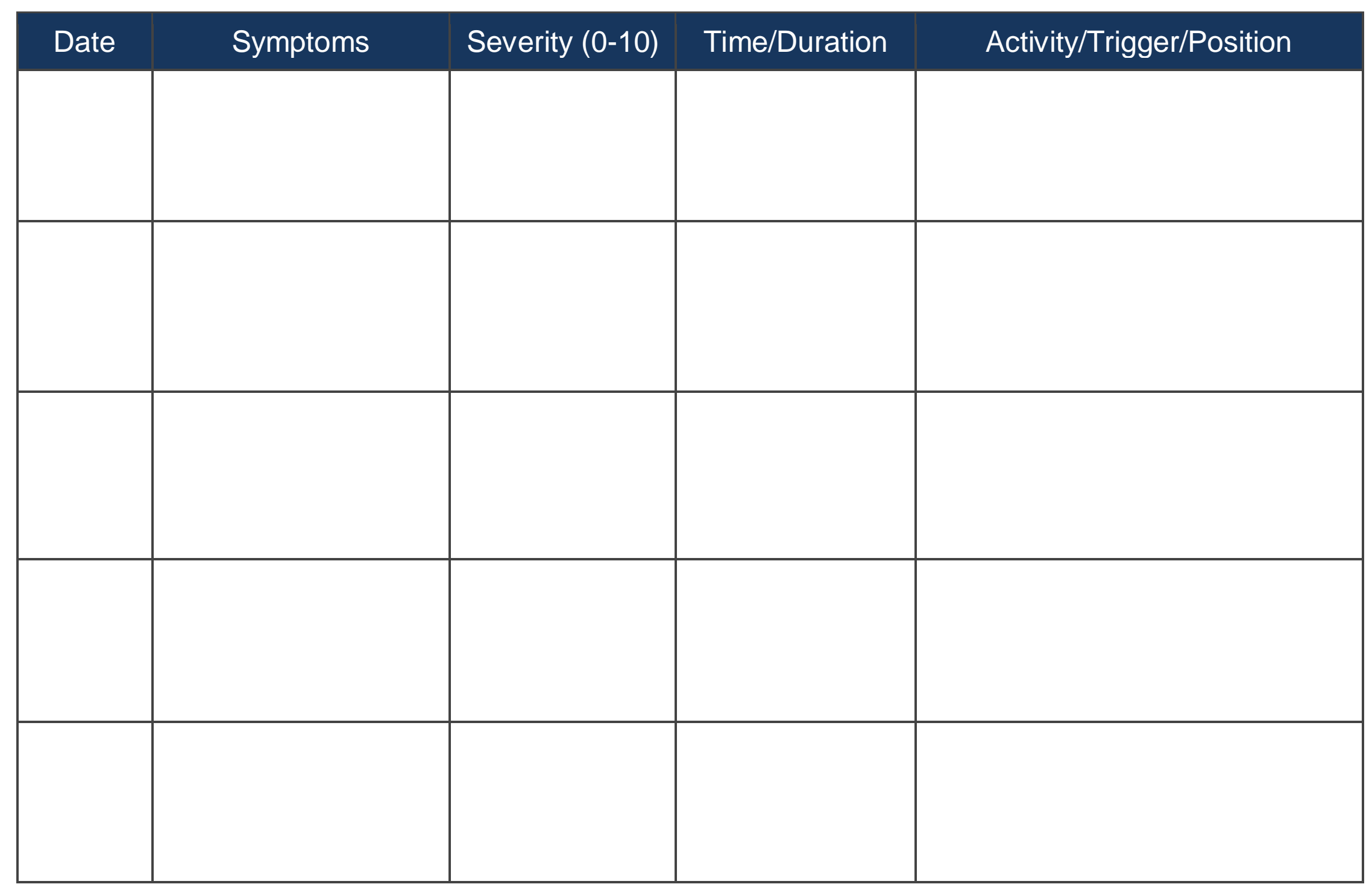




\section{Symptom Box}

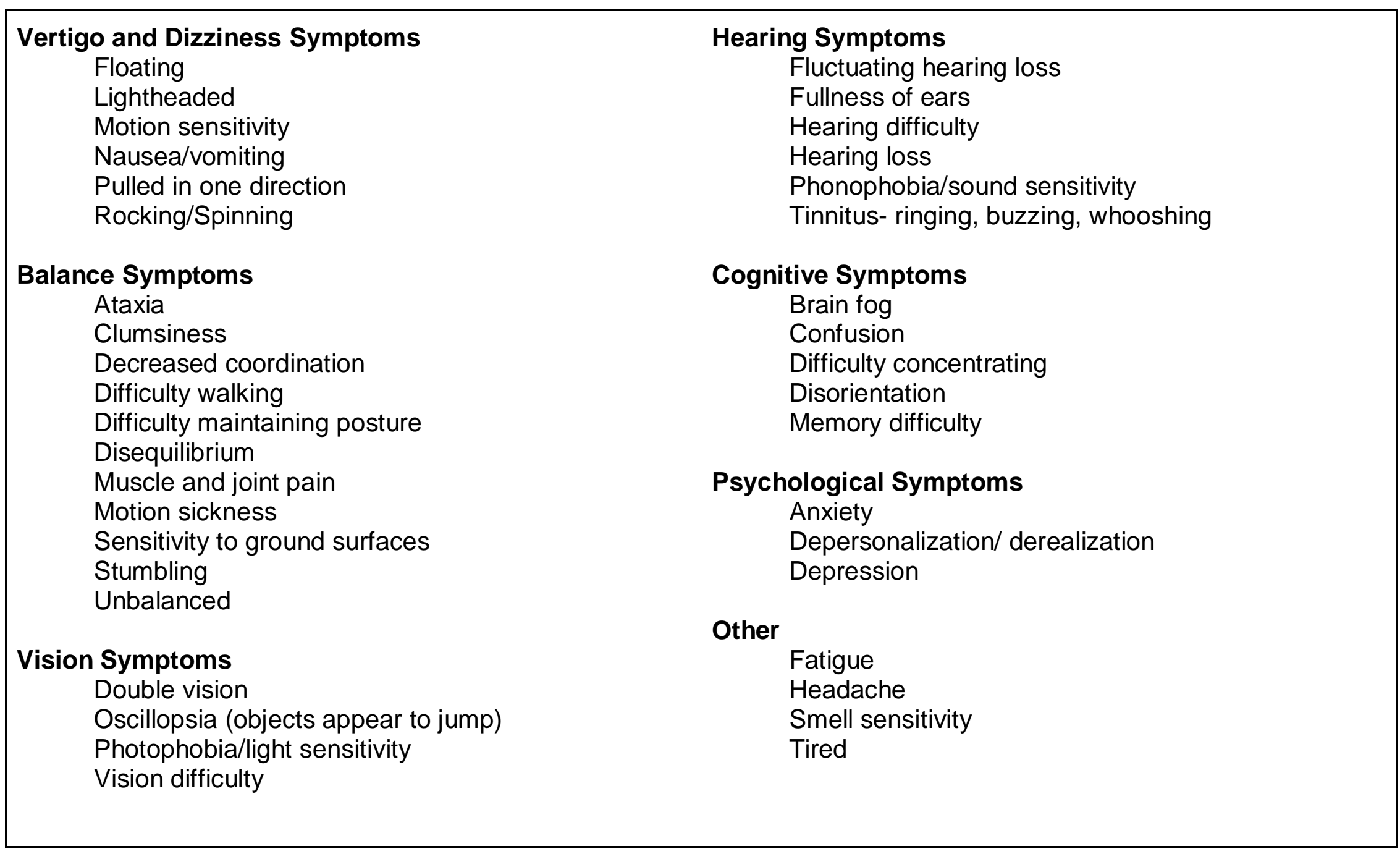




\section{B. My Vestibular Action Plan (VAP)}

Name:

DOB:

Treating physician/provider:

Emergency Contact:

\section{MY VESTIBULAR INFORMATION}

Diagnosis (Select applicable)

$\square$ BPPV

$\square$ Vestibular Migraine Meniere's Disease

$\square$ Perilymph Fistula

$\square$ Vestibular Neuritis

$\square$ Vestibular Hypofunction

$\square$ Other

$\square$ Unknown

Description:

Coexistent disorders:

Frequency, severity, and characteristics of symptoms:

(See Symptom Log from Module 1)

Functional ability: 
LIFESTYLE MANAGEMENT FOR VESTIBULAR DISORDERS

67

CURRENT MEDICATIONS (Include all medications, herbs, and supplements):

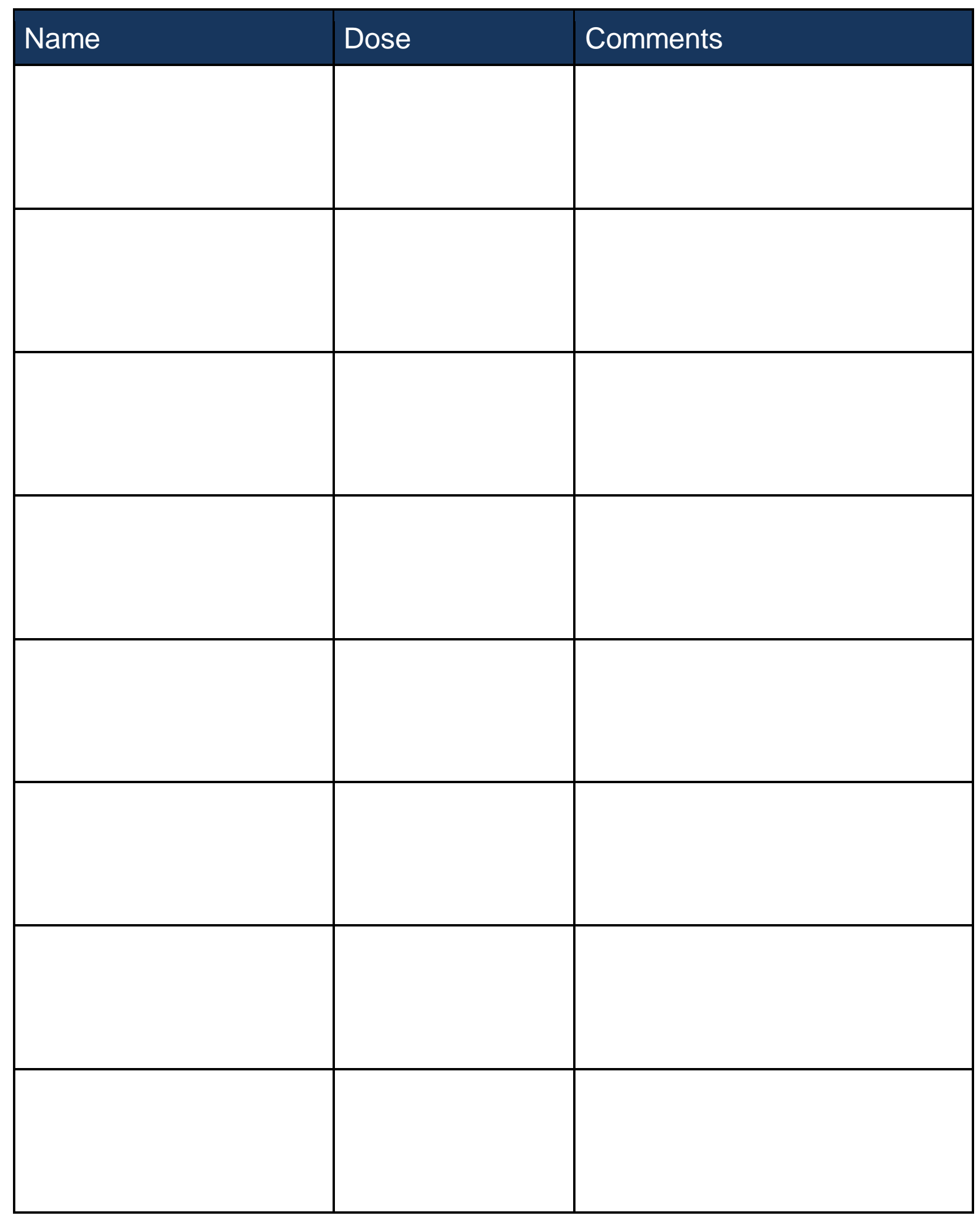




\section{MEDICAL HISTORY}

Prior treatments and responses:

Allergies:

Other: 


\section{MY HOME PLAN}

Symptom prevention

Rx Medication

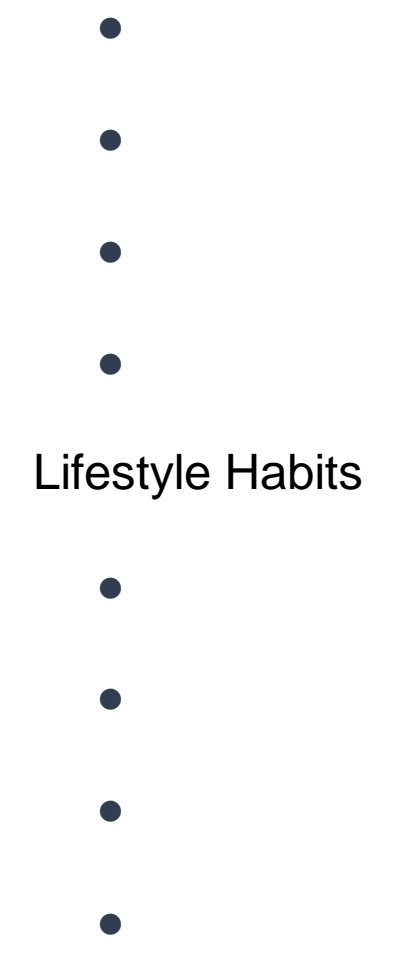

Other treatments

$\bullet$ 
Take the following steps at the start of a moderate to severe episode of vestibular symptoms:

Step 1:

Step 2:

Step 3:

\section{MY HOSPITAL PLAN}

Reasons to go to Urgent Care or Emergency Room

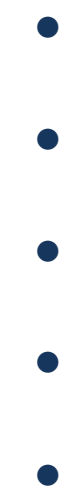

Who I can communicate my plan to: 


\section{Module 2: Self-Care and Routines}

\subsection{Discussion}

\section{Stress Management}

There is a high prevalence of anxiety in people with inner ear disorders (Best, Eckhardt-Henn, Tschan, \& Dieterich, 2009). The unpredictability, severity, and variability of vestibular symptoms can affect a person physically, cognitively, and emotionally. Vestibular disorders can cause a cycle of physical and emotional symptoms and responses. Symptoms often cause the person stress while stress can further evoke symptoms. This can lead to restriction of daily activities, avoidance of certain environments, social isolation, and role limitations (Cheng et al., 2012).

Vestibular disorders are described as "invisible" because people do not necessarily look sick. The occupational therapist should first aim to validate the person's experience. It is important for the individual to be able to identify stressors and key strategies to either decrease occurrence of symptoms or to improve functioning while experiencing symptoms. Stress management can be practiced in multiple ways through coping skills, engaging in everyday activities, and rest and sleep.

\section{Sleep Routine}

Sleep is an occupation that may be negatively impacted by vestibular vertigo (Albathi \& Agrawal, 2017). While vestibular pathologies have been found to impair sleep quality, sleep-related neuroplasticity could help in compensation processes (Besnard et al., 2018). Therefore, sleep is an important factor to address to increase the overall quality of life for individuals with vestibular disorders. 


\section{Eating Routine}

Healthful eating is important for any person. Certain dietary modifications have been found helpful in managing vestibular disorders. Some people find specific foods to trigger vestibular symptoms. It is often suggested for people to try a sodium restricted or gluten free diet in conjunction with other treatments. The topic of eating as it relates to nutrition should not be handled in isolation. Eating and nutrition should be linked to the concept of occupation, or how what we eat directly affects symptoms and engagement in daily activities. The occupational therapist should take the time to learn about the individual's nutritional needs and concerns to target educational information and discussion.

Things to consider for individuals with vestibular disorders:

- Adequate hydration

- Limiting alcohol consumption

- Decreasing salt intake

\section{Physical Activity}

People with vestibular disorders often adopt a sedentary lifestyle to avoid symptom-provoking movements. For example, people may restrict movement of their head and neck which leads to upper body stiffness and pain. Unfortunately, physical inactivity can lead to worsening of vestibular symptoms among other health problems. Physical movement is vital for a person with vestibular difficulties. It is imperative for the person to continue to stimulate the vestibular system through movement in order for the brain to compensate. Many people may be participating in a vestibular rehabilitation 
therapy program. The occupational therapist can facilitate discussion on incorporating those exercises into daily life and the importance of continuing to move.

It is important that the therapist evaluate the individual's level of ability and judgement before introducing any physical activity intervention.

\subsection{Goals}

- To educate on the relationship between stress and vestibular disorder symptoms. To identify stressors and develop strategies to cope.

- To identify relationship between quality of sleep and impact on vestibular symptoms. To incorporate a daily sleep routine and environmental modifications.

- To identify relationship between food choices and impact on vestibular symptoms. To incorporate nutrition recommendations into daily habits and routine.

- To identify relationship between physical activity and impact on vestibular symptoms. To incorporate physical activity into daily habits and routine.

\subsection{Suggested Discussion Questions}

- Stress Management

- How do you define stress?

-What are your stress triggers?

- How does stress affect your body?

- What simple strategies can you use to reduce stress?

- Sleep Routine

$\circ$ What is a sleep routine?

- Do you have a regular sleeping pattern? 
- What barriers keep you from a good night's sleep?

- What is a good sleep environment?

- Eating Routine

- How can healthy eating be incorporated into daily routine?

- How does nutrition relate to vestibular disorders and symptoms?

- How does everyday activity impact food cravings?

- Physical Activity

- How does exercise make you feel?

- How does exercise impact your vestibular symptoms?

- How do you incorporate exercise into your daily routine?

- Routine Management

What is your daily routine?

-When do you have the most energy to complete tasks?

- Does your daily schedule let you do the things you want and need to do?

- What are your major responsibilities?

- What do you like to do with your time?

- What do you value most in your life?

- What would you like your routine to be like?

\subsection{Suggested Activities}

\section{- Activity: Tai chi}

- Tai chi has been found to improve balance and flexibility in individuals with vestibular disorders (Huang, Nicholson, \& Thomas, 2019). Tai chi is a form of exercise that involves deep concentration, slow and fluid 
movements, and controlled breathing. Tai chi is comprised of a balance exercise sequence that can be done individually or in a series. Have the individual practice tai chi movements using handout 2.A. Discuss how these movements can be used for stress management during daily activities.

\section{- Activity: Practice breathing techniques}

- Have the individual practice breathing techniques using handout 2.B.

\section{- Activity: Practice relaxation techniques}

- Mindfulness is achieved by focusing your attention on the present moment and increasing awareness of the body and self. Mindfulness can help the individual improve their self-efficacy in management of their disorders (Hardison \& Roll, 2016). Have the individual practice relaxation techniques using handout 2.C.

\section{- Activity: Creating a Balanced Sleep Routine}

- Have the individual create a sleep routine using handout 2.D. Discuss sleep hygiene using handout 2.E.

\section{- Activity: Balanced Food Log}

- Have the individual record their daily intake of food to identify triggers from food or certain ingredients using handout 2.F. Discuss with the individual how this information can be used to modify their daily eating routine.

\section{- Activity: Sodium Handout}

- A sodium restricted diet is often recommended for individuals with Ménière's disease, secondary endolymphatic hydrops, and vestibular 
migraine. Some individuals find a high sodium diet to trigger vestibular symptoms. Discuss how sodium in the diet impacts the individual's daily activities using handout 2.G.

- Activity: Weekly Water Intake Tracker

- Discuss the importance of hydration with the individual using handout 2.H. Discuss ways to incorporate hydration into their daily routine. Have the individual track their daily water intake using handout 2.I.

\subsection{Handouts}

- Handout 2.A. Tai Chi Handout

- Handout 2.B. Breathing Techniques Handout

- Handout 2.C. Relaxation Techniques Handout

- Handout 2.D. Sleep Routine Handout

- Handout 2.E. Sleep Hyqiene Tips Handout

- Handout 2.F. Balanced Food Log Handout

- Handout 2.G. Sodium Handout

- Handout 2.H. Hydration Handout

- Handout 2.I. Weekly Water Intake Tracker

\subsection{Resources}

\begin{tabular}{|l|l|}
\hline AOTA OT Role in Sleep & $\frac{\text { https://www.aota.org/ /media/Corporate/Files/Ab }}{\text { outOT/Professionals/WhatlsOT/HW/Facts/Sleep- }}$ \\
\hline $\begin{array}{l}\text { fact-sheet.pdf } \\
\text { VeDA Tai Chi }\end{array}$ & $\frac{\underline{\text { https://vestibular.org/sites/default/files/page files/ }}}{\text { Documents/Improving\%20Balance\%20With\%20 }}$ \\
\hline $\begin{array}{l}\text { Vertigo and Psychological } \\
\text { Disturbances Article By Dr. } \\
\text { Timothy Hain }\end{array}$ & $\underline{\text { http://dizziness-and- }}$ \\
balance.com/disorders/psych/psych.htm \\
\end{tabular}




\begin{tabular}{|c|c|}
\hline $\begin{array}{l}\text { Mindfulness and Occupational } \\
\text { Therapy Article }\end{array}$ & $\begin{array}{l}\text { https://covalentcareers.com/resources/mindfulne } \\
\text { ss-occupational-therapy-new-secret-power/ }\end{array}$ \\
\hline $\begin{array}{l}\text { VeDA The Psychology of } \\
\text { Vestibular Disorders }\end{array}$ & $\begin{array}{l}\text { https://vestibular.org/sites/default/files/page files/ } \\
\text { Documents/Emotional\%20Aspects\%20of\%20Ves } \\
\text { tibular\%20Disorders Part\%202 57.pdf }\end{array}$ \\
\hline VeDA Relaxation Techniques & $\begin{array}{l}\text { https://vestibular.org/sites/default/files/page files/ } \\
\text { Documents/Relaxation\%20Techniques.pdf }\end{array}$ \\
\hline Mindfulness & $\begin{array}{l}\text { https://www.mindful.org/meditation/mindfulness- } \\
\text { getting-started/ }\end{array}$ \\
\hline VeDA Dietary Considerations & $\begin{array}{l}\text { https://vestibular.org/sites/default/files/page files/ } \\
\text { Documents/Dietary\%20Considerations\%20with\% } \\
\text { 20Secondary\%20Endolymphatic\%20Hydrops\%2 } \\
\text { C\%20Meniere\%27s\%20Disease\%20\%26\%20Ve } \\
\text { stibular\%20Migraine.pdf }\end{array}$ \\
\hline $\begin{array}{l}\text { Office of Disease Prevention and } \\
\text { Health Promotion 2015-2020 } \\
\text { Dietary Guidelines for Americans }\end{array}$ & $\begin{array}{l}\text { https://health.gov/dietaryguidelines/2015/guidelin } \\
\text { es/ }\end{array}$ \\
\hline $\begin{array}{l}\text { American Heart Association } \\
\text { Sodium Resources }\end{array}$ & $\begin{array}{l}\text { https://www.heart.org/en/healthy-living/healthy- } \\
\text { eating/eat-smart/sodium }\end{array}$ \\
\hline $\begin{array}{l}\text { Office of Disease Prevention and } \\
\text { Health Promotion Physical Activity } \\
\text { Guidelines for Americans }\end{array}$ & $\begin{array}{l}\text { https://health.gov/paguidelines/second- } \\
\text { edition/pdf/Physical Activity Guidelines 2nd edi } \\
\text { tion.pdf }\end{array}$ \\
\hline
\end{tabular}

\section{References}

Albathi, M., \& Agrawal, Y. (2017). Vestibular vertigo is associated with abnormal sleep duration. Journal of Vestibular Research, 27(2-3), 127-135. https://doi.org/10.3233/VES-170617

Besnard, S., Tighilet, B., Chabbert, C., Hitier, M., Toulouse, J., Le Gall, A., ... Smith, P. F. (2018). The balance of sleep: Role of the vestibular sensory system. Sleep Medicine Reviews, 42, 220-228. https://doi.org/10.1016/j.smrv.2018.09.001 
Best, C., Eckhardt-Henn, A., Tschan, R., \& Dieterich, M. (2009). Psychiatric morbidity and comorbidity in different vestibular vertigo syndromes: Results of a prospective longitudinal study over one year. Journal of Neurology, 256(1), 5865. https://doi.org/10.1007/s00415-009-0038-8

Cheng, Y.-Y., Kuo, C.-H., Hsieh, W.-L., Lee, S.-D., Lee, W.-J., Chen, L.-K., \& Kao, C.-L. (2012). Anxiety, depression and quality of life (QoL) in patients with chronic dizziness. Archives of Gerontology and Geriatrics, 54(1), 131-135. https://doi.org/10.1016/j.archger.2011.04.007

Hardison, M. E., \& Roll, S. C. (2016). Mindfulness interventions in physical rehabilitation: A scoping review. American Journal of Occupational Therapy, 70(3), 7003290030p1.

Huang, H.-W., Nicholson, N., \& Thomas, S. (2019). Impact of tai chi exercise on balance disorders: A systematic review. American Journal of Audiology, 28(2), 391-404. https://doi.org/10.1044/2018 AJA-18-0115

National Sleep Foundation. (2019). Sleep hygiene. Retrieved from https://www.sleepfoundation.org/articles/sleep-hygiene 


\section{A. Tai Chi Handout}

Note: This is an introduction to Tai Chi. Use these principles during exercise movements and during daily activities:

- Focus your mind at the center of your mass, remember to breathe

- Relax completely- do what feels good, take rest breaks

- Keep weight underside

○ Keep head, neck, and spine aligned

- Feel anchored to the ground as you move

- Practice slow, deliberate, continuous movement

\section{Exercises}

- Warm Up

- Stand or sit with feet together, hands at side

- Look forward

- Close mouth, breathe through nose

- Relax mind and body

- Align posture

- Front-to-back wave

- Begin with hands at center of body with palms facing (but not touching) each other

- Swing hands away and down

- Return hands to center

○ Repeat

- Pushing hands

- Begin with hands at center of body with palms facing (but not touching) each other

- Push hands to one side, extending arms

- Bring hands back to center 
- Repeat on other side

- Forward Ball Hold

○ Bend knees slightly, shift weight to right foot, lift left heel

- Gradually distribute weight evenly to both feet

○ Extend arms slightly out

- Lift arms up slowly, palms down, shoulder's width apart

- Sit deeper and make big circle with arms (as if you are holding a ball)

- Turning the Wheel

- From the "Ball Hold" posture, slowly shift weight to left leg and lift right heel

- Turn 45 deg, move arms to one side in "wave" motion

- Touch right heel down, shift weight to right front leg

- Shift weight onto left rear leg, arms move circularly down

○ Repeat motions

\author{
Adapted from https://www.dizziness-and-balance.com/taichi/handout.pdf \\ https://www.stjoes.ca/patients-visitors/patient-education/patient-education:-p-t/ways-to-control-your- \\ breathing---resp-rehab-pdf
}




\section{B. Breathing Techniques Handout}

Deep Belly Breathing (Diaphragmatic Breathing)

- While sitting, place hands on belly

- Breathe in through nose and out through pursed lips

- Move belly outwards with each inhalation

- Relax belly back in on each exhalation

This breathing technique can be used throughout daily activities.

When can you use this technique? 


\section{C. Relaxation Techniques Handout}

Meditation

- Sit or lie down with eyes closed

- Bring awareness and attention to breathing

- When thoughts, feelings, or sounds occur observe and accept them

- When your attention has drifted, simply note that and bring attention back to breathing

Body Scan

- Sit or lie down with eyes closed

- Focus attention on various areas of body and sensations felt

- Focus on slowly tensing and relaxing each muscle group

Mindful Movement

- Choose a routine task or activity such as tooth brushing, showering, eating

- Notice your body positions

- Tune into your senses

- Notice your thoughts and emotions

- Notice the environment

When can you incorporate these tools during your day? 
2.D. Creating a Balanced Sleep Routine Handout

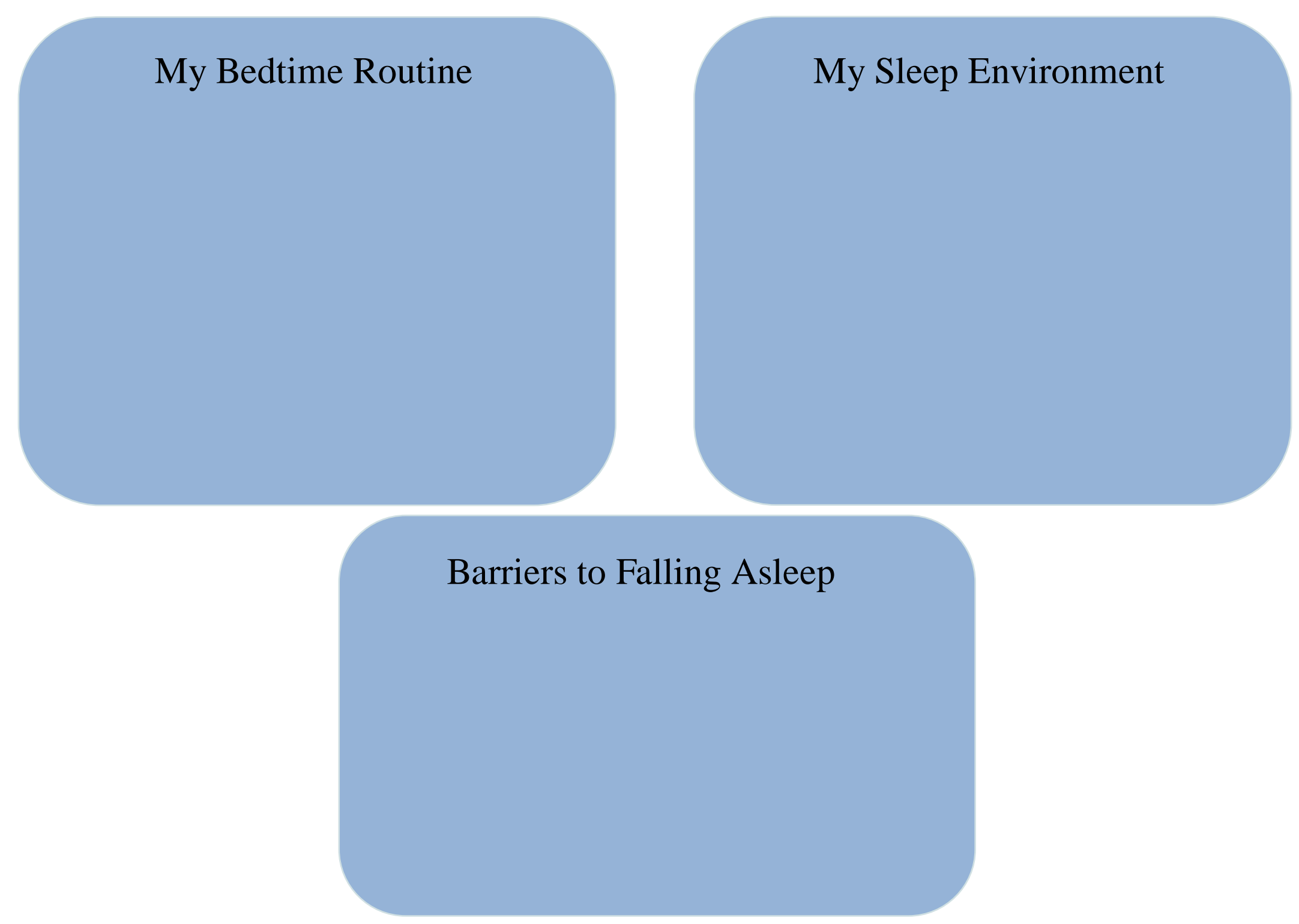




\section{E. Sleep Hygiene Handout}

Sleep hygiene is defined as practices and habits that support quality sleep at night and therefore quality physical and mental health during the day (National Sleep Foundation, 2019). Some ideas include:

- Maintain a regular sleep and wake schedule, even on weekends

- Limit daytime naps to 30 minutes or less

- Avoid stimulants (example: caffeine, nicotine) near bedtime

- Get regular exercise

- Adequate exposure to natural light during the day

- Establish a regular bedtime routine or ritual

- Use bedroom primarily for sleeping

- Evaluate bedroom environment (temperature, sound, light)

- Take a warm bath

- Journal

- If you can't fall asleep after 30 minutes, get up and do something that is not stimulating such as reading

- Avoid bright lights from TV screen or computer screen an hour before bedtime 
2.F. My Balanced Food Log Handout

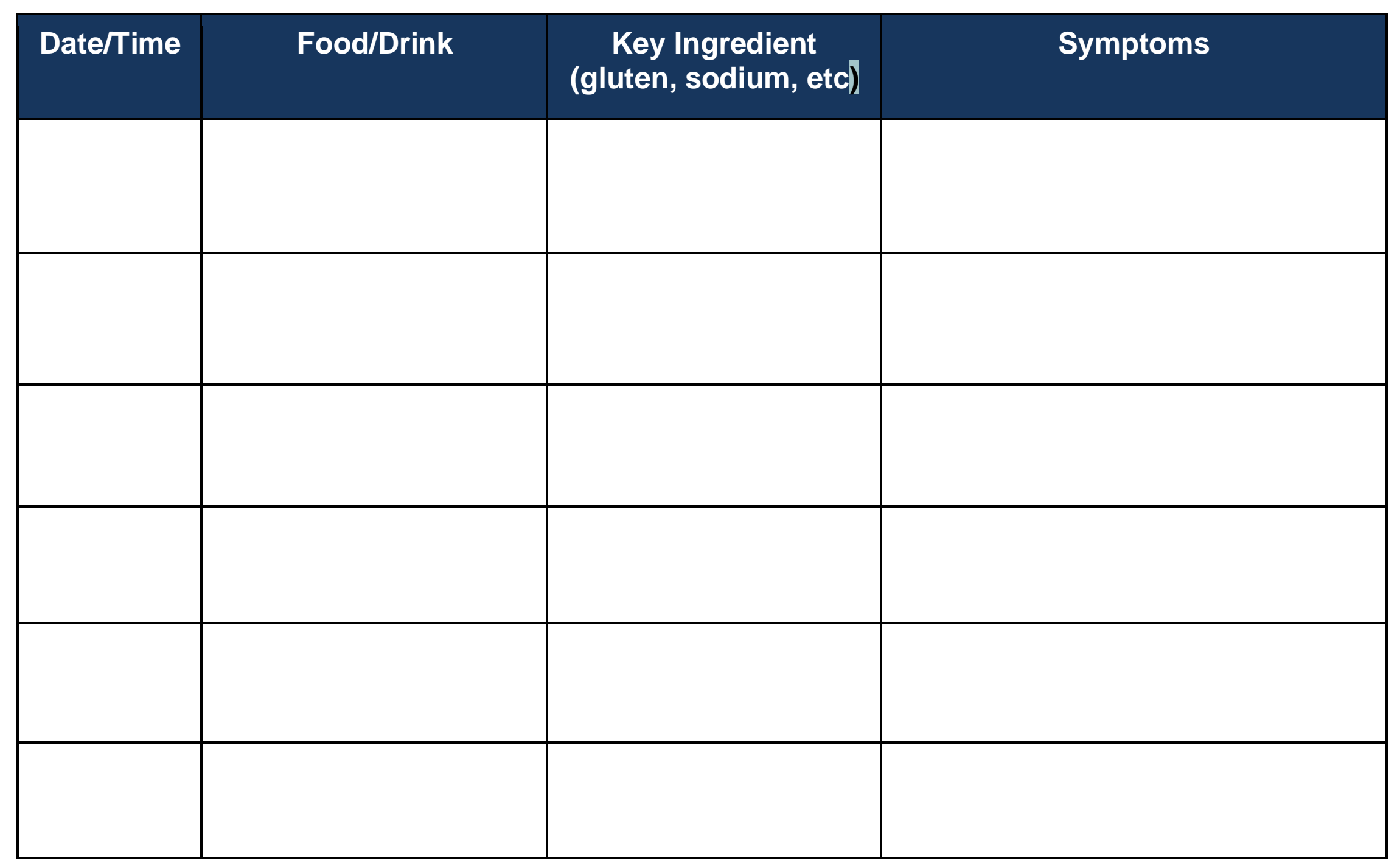




\section{G. Sodium Handout}

How can I reduce sodium when preparing food at home?

- Choose packaged foods carefully

- Select low sodium condiments

- Use onions, garlic, herbs, spices, citrus, etc in place of salt

- Combine lower sodium versions of food with regular versions

- Cook by grilling, braising, roasting, searing, and sauteing

- Choose foods with potassium to counter the effects of sodium

How can I reduce sodium when eating at restaurants?

- Ask for your dish to be made without extra salt

- Ask about sodium content of menu items

- Be aware of foods that are pickled, brined, cured, smoked, etc

- Control portion sizes 


\section{H. Hydration Handout}

Hydration Tips

- Have hydrating drinks readily available

- Carry a reusable water bottle

- Hydrate throughout the day

- Have reminders posted in visible areas

- Incorporate hydration into daily routine

- Get creative with drinks such as using a variety of drinking vessels and glasses

Use the space below to write down strategies to increase your hydration throughout the day. 

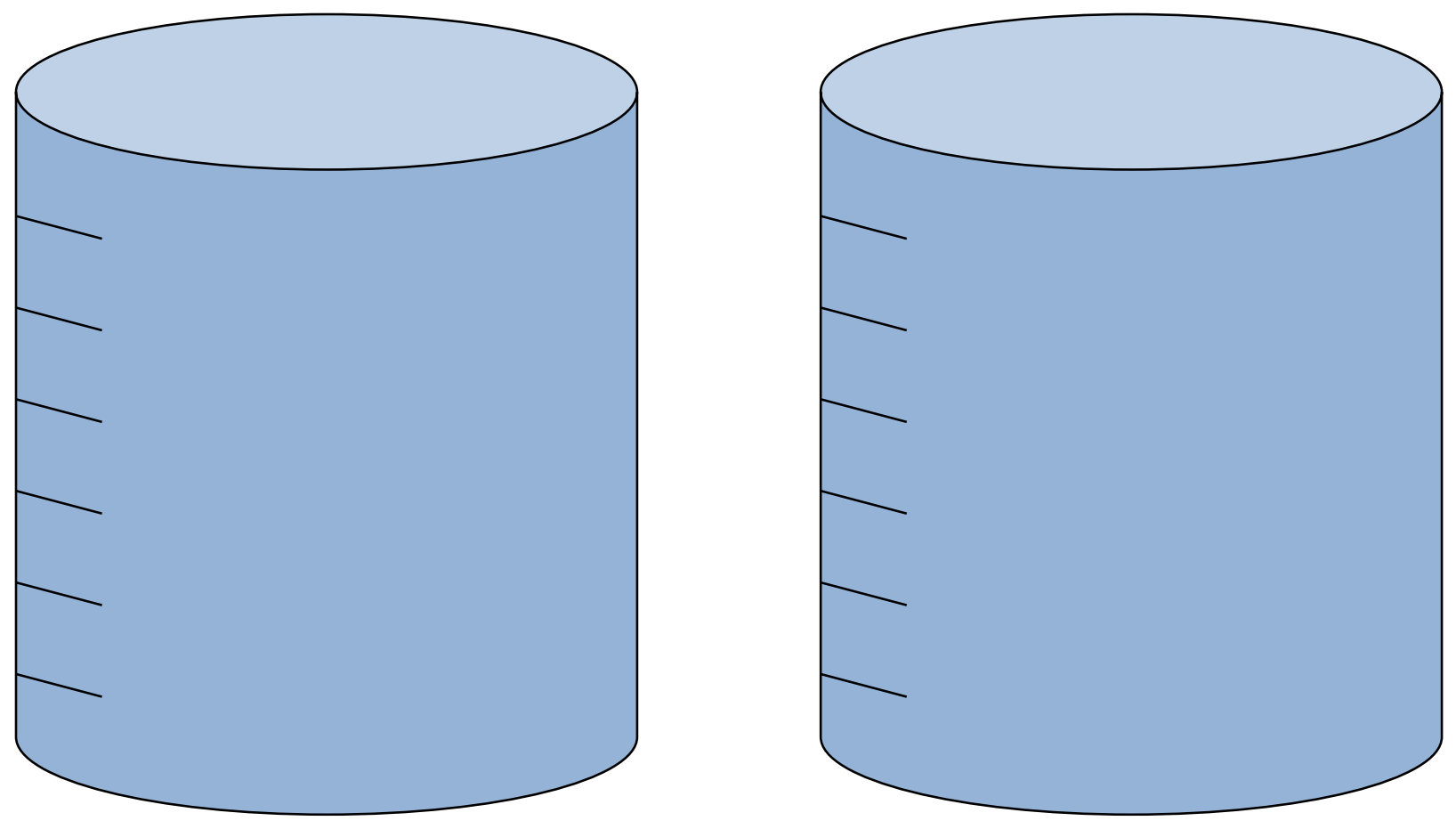

A. How much water I currently drink

B. Hydration goal 


\section{I. Weekly Water Intake Tracker}

Directions: Cross out the water drops as you drink your daily water.

Week:

Wednesday




\section{Module 3: Health Management and Advocacy}

\subsection{Discussion}

\section{Navigating and Accessing Healthcare}

It is common for people with vestibular disorders to see multiple providers before finding the correct help. The reason may be due to most healthcare providers not specializing in the vestibular system. A person may see their primary physician with the complaint of dizziness and vertigo. The physician will test for more serious causes of dizziness such as stroke or heart attack and not find a root cause. The person is often told to live with their symptoms and at the most given medication to mask the symptoms. The primary physician may refer the person to a neurologist or otolaryngologist, however these specialists do not always have an inner ear subspecialty. The most specialized physician is called an otoneurologist or neurotologist. These physicians specialize in assessing and treating the brain and the inner ear (vestibular system).

In this day, patients are increasingly required to play an active role in the management of their own health care. This module will focus on facilitating discussion about navigating the current health care system and finding qualified vestibular specialists. This module can be tailored to the individual's health literacy and health care system concerns.

\section{Medication Management}

People with vestibular disorders may be taking multiple medications. Medications will depend on whether the person is in an acute phase or chronic phase of a vestibular disorder. Certain medications can have an effect on the brain's ability to compensate 
during vestibular rehabilitation. Medication management is an important topic to discuss because of the impact medication can have on managing one's condition and engaging in daily activities. The occupational therapist should take the time to learn about common medications used for vestibular disorders.

\subsection{Goals}

- To play an active role in the management of own care

- To successfully navigate the healthcare system and interact with healthcare professionals

- To adhere to a medication schedule.

- To identify the relationship between medication and the impact on vestibular symptoms.

\subsection{Suggested Discussion Questions}

- Navigating and Accessing Healthcare

- How do you currently access information about your health and health care?

- How sure are you that you would be able to communicate your health issues and needs to your provider?

- Share a time when you were unsure about what a health provider told you?

- Medication Management

- How do you currently keep track of the medications you are taking? 


\subsection{Suggested Activities}

- Activity: Vestibular medical terminology

- Review medical terminology frequently used during doctor visits using handout 3.A.

\section{- Activity: Role Play a Doctor Appointment}

- Have the individual practice asking questions about medications, diagnoses, and procedures.

\section{- Activity: Fill out medication log}

- Record prescriptions, over-the-counter medications, supplements, vitamins, herbs, etc. using handout 3.B. Discuss the effects medications and other supplements have on daily activities.

\subsection{Handouts}

- Handout 3.A. Vestibular Medical Terminology Handout

- Handout 3.B. My Medication Log Handout

\subsection{Resources}

\begin{tabular}{|c|c|}
\hline $\begin{array}{l}\text { VeDA Finding a Vestibular } \\
\text { Specialist }\end{array}$ & $\begin{array}{l}\text { https://vestibular.org/finding-help- } \\
\text { support/provider-directory }\end{array}$ \\
\hline VeDA Questions for Your Doctor & $\begin{array}{l}\text { https://vestibular.org/sites/default/files/ } \\
\text { page_files/Documents/Questions\%20for\%20you } \\
\text { r\%20doctor.pdf }\end{array}$ \\
\hline $\begin{array}{l}\text { American Academy of Neurology } \\
\text { Article: How to Establish a Strong } \\
\text { Doctor-Patient Relationship }\end{array}$ & $\begin{array}{l}\text { https://www.brainandlife.org/articles/a-strong- } \\
\text { relationship-with-your-neurologist-is-important- } \\
\text { these-tips/ }\end{array}$ \\
\hline $\begin{array}{l}\text { AOTA Statement on Health } \\
\text { Literacy }\end{array}$ & $\begin{array}{l}\text { https://ajot.aota.org/article.aspx?articleid }=18652 \\
\underline{02}\end{array}$ \\
\hline VeDA What is VRT? & $\begin{array}{l}\text { https://vestibular.org/sites/default/files/page files } \\
\text { IDocuments/Vestibular\%20Rehabilitation 1pg.p } \\
\text { df }\end{array}$ \\
\hline
\end{tabular}




\begin{tabular}{|l|l|}
\hline & \\
\hline Finding a Vestibular Rehabilitation & http://dizziness-and- \\
Therapist & $\begin{array}{l}\text { balance.com/treatment/rehab/VRT- } \\
\text { providers.html }\end{array}$ \\
\hline VeDA Information on Medication & $\underline{\text { https://vestibular.org/understanding-vestibular- }}$ \\
& $\underline{\text { disorders/treatment/vestibular-medication }}$ \\
\hline
\end{tabular}




\section{A. Vestibular Medical Terminology Handout}

Vertigo- a spinning or whirling sensation a person feels when they are not moving

Vestibular system- the system in the inner ear that helps control balance and equilibrium

Semicircular canals- canals located in the inner ear filled with fluid; detect rotational movement of the head

VNG/ENG- videonystagmography/electronystagmography; test to measure and record eye movements during a variety of tasks and conditions

VEMP- vestibular evoked myogenic potentials; a test involving measuring a response to sound to test the function of sensory organs in the inner ear

Caloric test- heated or cooled air (or water) is introduced into the ear canal to evaluate inner ear function

Crystals (otoconia)- small crystals normally located in the inner ear; sometimes the crystals can detach and cause dizziness

Canalith repositioning procedure- maneuvers performed by a professional involving specific head and trunk movements to move "crystals" back into place; examples include Epley maneuver and SemontLiberatory maneuver

Vestibular rehabilitation therapy- specific head, body, and eye exercises used to retrain the brain

Nystagmus- reflexive eye movements characterized by eyes drifting away from center and then quickly moving back to center; can be observed in normal and abnormal conditions

Tinnitus- ringing, roaring, buzzing, whooshing, or other noises in the ear 
3.B. My Medication Log Handout

Directions: Record prescriptions, over-the-counter medications, supplements, vitamins, herbs, etc.

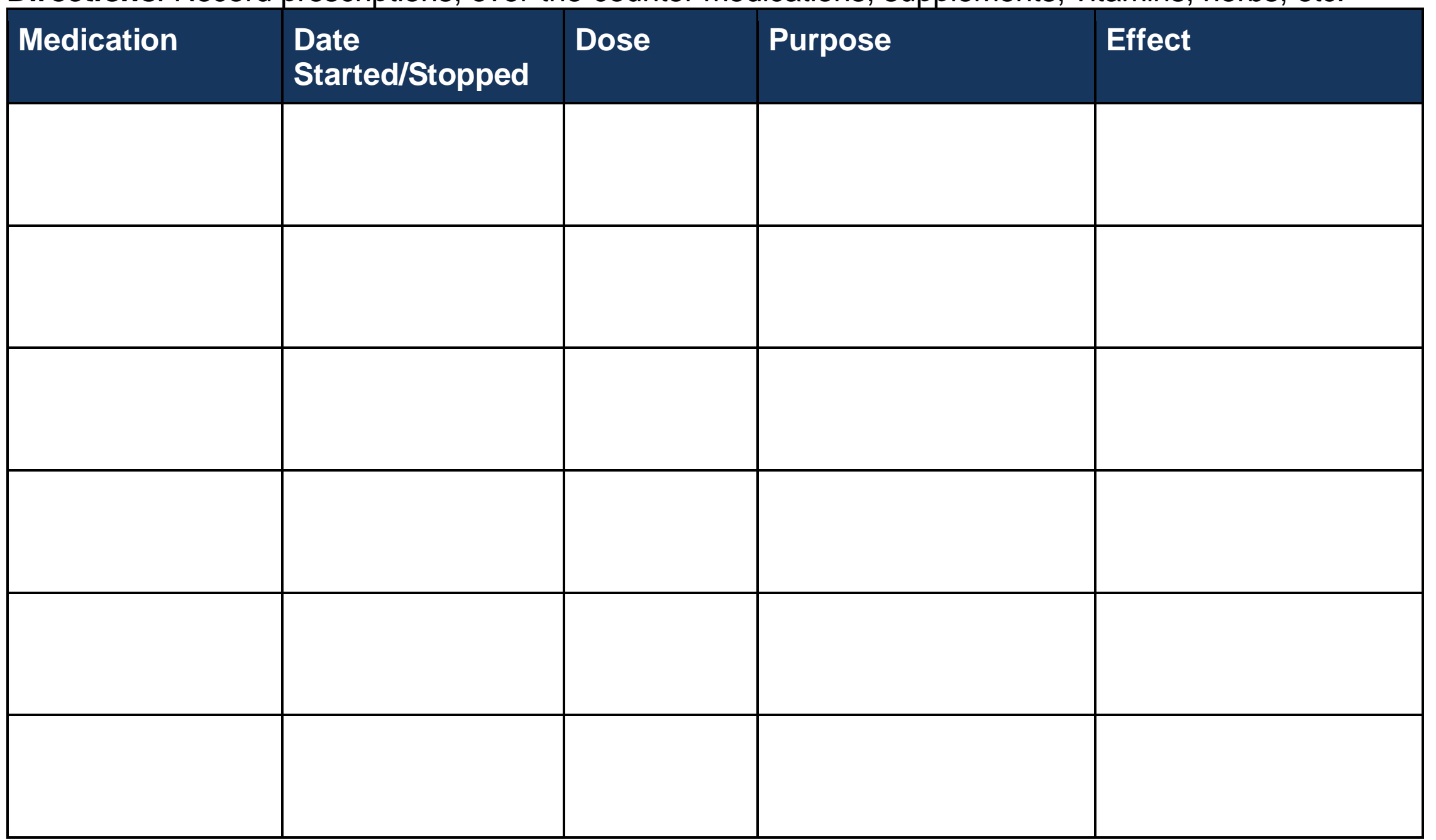




\section{Module 4: Activities of Daily Living}

\subsection{Discussion}

Home Management and Fall Prevention

Because the vestibular system plays a large role in balance, falls are a major concern for people with vestibular disorders. Keeping or creating a safe environment involves the use of the visual system, proprioception system, and vestibular system. This module will focus on facilitating discussion about the impact of safe environments on supporting the performance of everyday occupations.

\subsection{Goals}

- To identify the relationship between vestibular symptoms and home safety.

- To identify home adaptations and modifications to promote ability to perform occupations in a safe environment.

\subsection{Suggested Discussion Questions}

- Home Management and Safety

- Why is a safe environment important?

- What makes the home environment safe?

-What adaptations have you made around your home to improve safety?

- What might be some causes of falls in your home?

-What might be some causes of falls in the community setting?

- What things do you do to reduce your risk for falls or prevent future falls? 


\subsection{Suggested Activities}

- Activity: Home Safety Self-Evaluation

- Have the individual complete a home safety self-evaluation using handout 4.A. Recommend home safety tips using handout 4.B.

- Activity: Adaptive Equipment

- Recommend modifications and adaptations using handout 4.C.

- Activity: Fall Self Reflection and Prevention Tips

- Have the individual complete a self-reflection on how falls relate to daily life using handout 4.D. Discuss handout 4.E.

- Activity: Rehearse safe body mechanic and energy conservation techniques

\subsection{Handouts}

- Handout 4.A. Home Safety Self-Evaluation

- Handout 4.B. $\underline{\text { Home Safety Tips }}$

- Handout 4.C. Adaptive Equipment Handout

- Handout 4.D. Fall Self Reflection Handout

- Handout 4.E. Fall Prevention Tips

\subsection{Resources}

\begin{tabular}{|l|l|}
\hline $\begin{array}{l}\text { VeDA Fall Prevention } \\
\text { and Home Safety }\end{array}$ & $\begin{array}{l}\text { https://vestibular.org/sites/default/files/page files/Document } \\
\text { s/Fall-Prevention-and-Home-Safety 101.pdf }\end{array}$ \\
\hline $\begin{array}{l}\text { AOTA Fall Prevention } \\
\text { Resources }\end{array}$ & https://www.aota.org/Practice/Productive-Aging/Falls.aspx \\
\hline $\begin{array}{l}\text { AOTA Fall Prevention } \\
\text { Tips }\end{array}$ & $\underline{\text { https://www.aota.org/ /media/Corporate/Files/AboutOT/cons }}$ \\
umers/Adults/Falls/Fall\%20Prevention\%20Tip\%20Sheet.pdf \\
\hline
\end{tabular}




\section{A. Home Safety Self-Evaluation}

Directions: Take a mental "walk" through your house. Make note of any potential safety hazards.

\begin{tabular}{|c|c|c|c|c|}
\hline & Living Room & Bedroom & Bathroom & Kitchen \\
\hline Eye Level & & & & \\
\hline $\begin{array}{l}\text { Trunk } \\
\text { Level }\end{array}$ & & & & \\
\hline $\begin{array}{l}\text { Ground } \\
\text { Level }\end{array}$ & & & & \\
\hline
\end{tabular}


Eye level: Vision, lighting and head movements

- What is the lighting like?

- Where do you access the light switches or lamps?

- Is the lighting ample enough to walk around safely at night?

- Can you safely reach needed items placed overhead?

Trunk level: Arms and hips, places to hold, places to sit

- If you experienced vestibular symptoms suddenly, are there safe places to sit down?

- Are the heights of the chairs, beds, and tables appropriate?

- Are there safe, stable places to grab onto if needed?

Ground level: Walkways, pathways, floors, surfaces

- What are the floor surfaces made of? Are the surfaces stable?

- Are there clear pathways in each room?

- Are there rugs, mats, or other items on the floor 


\section{B. Home Safety Tips Handout}

\section{Entrances and Exits}

- Locks should be accessible and in working order.

- Ensure mats and rugs are secure to prevent any tripping hazards.

- Consider installing a railing on the sides of steps.

\section{Bedroom}

- When waking up in the morning, "wake up" your vestibular system by taking a few moments sitting on the side of the bed. Turn head up, down, side-to-side.

- Keep any needed assistive devices at bedside.

\section{Bathroom}

- Ensure adequate lighting.

- Consider installing grab bars in shower and/or by toilet.

- Consider installing a hand-held shower head if bending neck/head causes vestibular symptoms.

\section{Other}

- Keep garden/yard pathway clear. Consider a concrete path versus stepping stones for greater stability.

- Keep adequate lighting overhead or on floor.

\section{Comments:}




\section{C. Adaptive Equipment Handout}

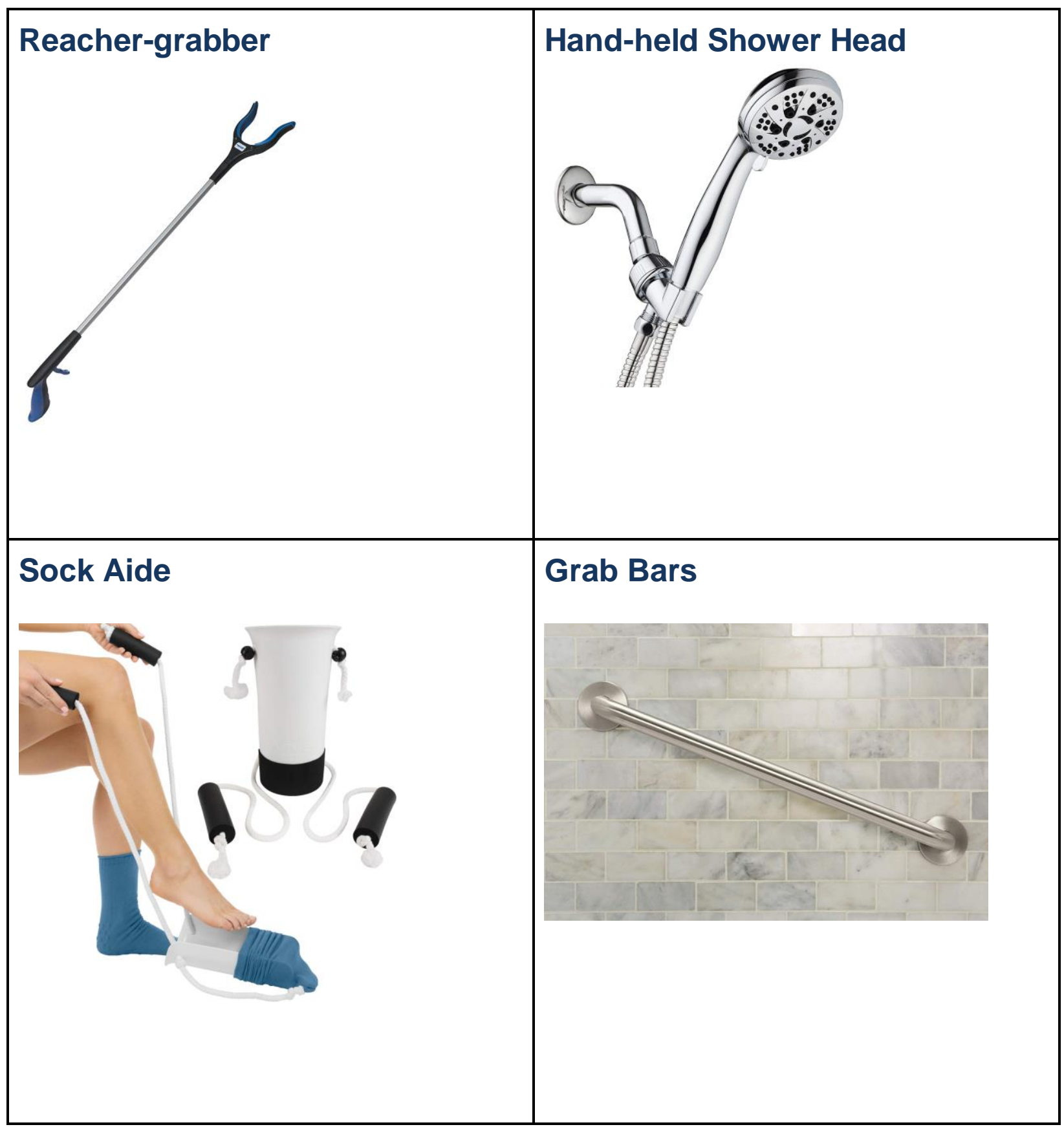




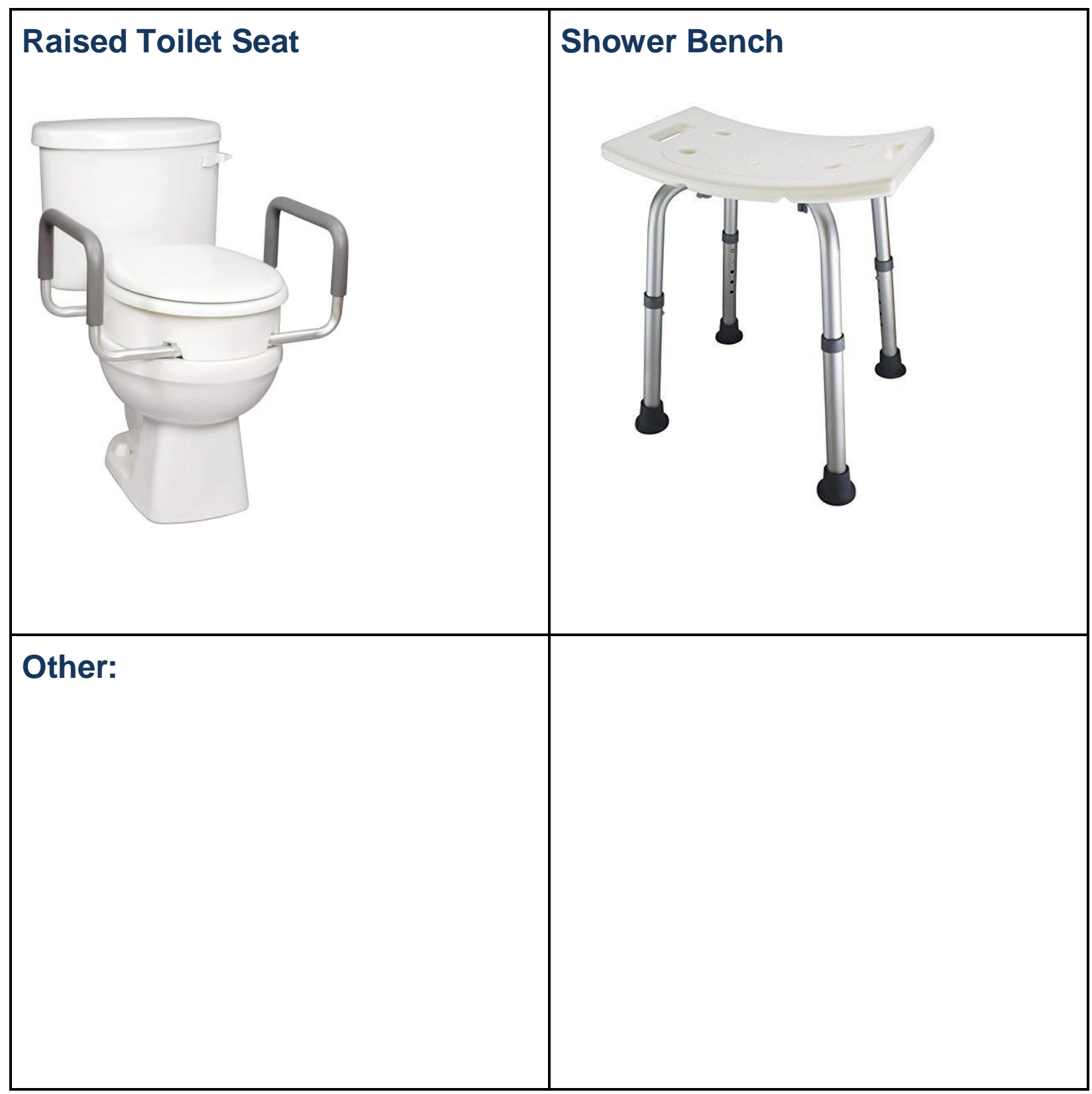

Images retrieved from www.amazon.com

When can I use this adaptive equipment: 


\section{D. Falls Self-Reflection}

Reasons I may fall include:

Places inside/outside my house I would most likely fall include:

Situations in which I would most likely fall include:

I can prevent falls by:

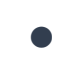

de:

$\bullet$

$\bullet$

$\bullet$

$\bullet$

$\bullet$

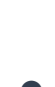

- 


\section{E. Fall Prevention Tips}

- Identify potential risk factors early

- Use caution when getting up quickly or changing positions

- Wear secure, nonskid shoes

- Make sure clothes fit securely so they don't catch on something

- Minimize clutter

- Keep pathways clear

- Move electric cords or wires away from walkways

- Keep steps and walkways in good repair

- Use nonskid mats or throw rugs

- Remove rugs or mats that slide or curl up on edges

- Get vision and hearing checked regularly

- Pay attention to new medications

- Limit intake of alcohol

- Have family or friends move most-used items so they are accessible

- Maintain attention on one task at a time

- Install grab bars

- Install ramps

- Use recommended assistive devices

- Maintain a suitable exercise program 


\section{Module 5: Community Integration and Work}

\subsection{Discussion}

\section{Transportation}

Driving is an important occupation for adults. Vestibular symptoms such as dizziness, vertigo, visual disturbances, and nausea can have an impact on safe driving. While driving with these symptoms is not recommended, many adults with vestibular disorders need to go to work, medical appointments, therapy appointments, and perform other activities of daily living. Driving after a doctor appointment or vestibular rehabilitation therapy can be especially challenging because testing and treatment at these appointments are designed to elicit symptoms.

The occupational therapist should discuss how transportation and occupation affect each other in the context of the person's specific vestibular concerns. If a person has more detailed concerns about their ability to drive safely, referral to a certified driving rehabilitation specialist or program may be beneficial. Information can be found in the resource section.

\section{Social Interaction}

People with vestibular disorders often restrict their daily activities and participation in social activities resulting in social isolation (Harun, Li, Bridges, \& Agrawal, 2016). This topic will focus on identifying how vestibular symptoms impact social participation, nurturing current relationships, and finding support within the vestibular community. This will create an opportunity for reflection on the place relationships and community have on the person's life. 


\section{Work}

Living with a vestibular disorder can affect a person's life in many ways including the ability to work. People report taking time away from work due to symptoms. The work environment is not always conducive to working with symptoms due to the time constraints, visual requirements from computer screens and overhead lighting, and postural requirements. The occupational therapist can facilitate occupational selfanalysis of the person by exploring how the participant engages in work activities.

\subsection{Goals}

- To identify the impact vestibular symptoms have on transportation, social interaction, and work.

- To increase ability to perform social and work occupations.

\subsection{Suggested Discussion Questions}

- Transportation

- What types of transportation do you use regularly?

- What types of transportation do you use when you experience vestibular symptoms?

- How do your vestibular symptoms impact your ability to drive?

- What types of transportation are available to you?

- How can different forms of transportation open up your activity options?

- What are some positive aspects of using different forms of transportation?

- Social Interaction

- Describe your relationships with people in your life?

- How do social relationships affect occupations? 
- How does participation in an activity differ when you are alone versus with other people?

- How do vestibular symptoms affect social relationships?

- Work

- How does working make you feel?

- How does your vestibular disorder impact your ability to work?

- Have you ever had to miss work because of vestibular symptoms?

- What equipment or work conditions would improve your ability to perform your job?

\subsection{Suggested Activities}

- Activity: Creating a Transportation Resource List

- Create a transportation resource list using handout 5.A that includes the name of the service, phone number, website, requirements, cost, and comments

\section{- Activity: Find a vestibular support group}

- Have the individual find a vestibular support group in their area using VeDA's support group directory (https://vestibular.org/finding-helpsupport/support-directory). There are also online support groups available if none are listed in the individual's nearby area.

\section{- Activity: Workplace Accommodations}

- Have the individual complete handout 5.B. 
- Activity: Role play speaking with boss or manager about workplace adjustments and accommodations

\subsection{Handouts}

- Handout 5.A. Transportation Resources Handout

- Handout 5.B. Workplace Accommodation Handout

\subsection{Resources}

\begin{tabular}{|l|l|}
\hline $\begin{array}{l}\text { AOTA Driving and } \\
\text { Community Mobility }\end{array}$ & $\underline{\text { https://www.aota.org/Practice/Productive- }}$ \\
\cline { 2 - 2 } AOTA Finding a Driving & $\underline{\text { https://myaota.aota.org/driver search/index.aspx? }}$ \\
\hline Specialist & 691965460.1526618974 \\
\hline $\begin{array}{l}\text { National Highway Traffic } \\
\text { Safety Administration }\end{array}$ & $\underline{\text { https://www.nhtsa.gov }}$ \\
\hline VeDA Disability Resources & $\underline{\text { https://vestibular.org/living-vestibular-disorder/tips- }}$ \\
\hline
\end{tabular}

\section{References}

Harun, A., Li, C., Bridges, J. F., \& Agrawal, Y. (2016). Understanding the experience of age-related vestibular loss in older individuals: A qualitative study. Patient, 9(4), 303309. doi:10.1007/s40271-015-0156-6 
5.A. Transportation Resource Worksheet

\begin{tabular}{|c|c|c|c|c|c|}
\hline Name & Phone & Website & Requirements & Cost & Comments \\
\hline & & & & & \\
\hline & & & & & \\
\hline & & & & & \\
\hline & & & & & \\
\hline & & & & & \\
\hline & & & & & \\
\hline & & & & & \\
\hline & & & & & \\
\hline & & & & & \\
\hline & & & & & \\
\hline & & & & & \\
\hline
\end{tabular}


I should not drive when I experience these symptoms: 


\section{B. Workplace Accommodation Tips Handout}

- Adjust work station so head is positioned at neutral angles

- Limit screen time

- Wear anti-glare glasses

- Lamps over work surfaces

- Change brightness on computers and phones

- Green or blue background in place of black/white

- Communicate with coworkers

- Monitor noise levels

- Utilize relaxation techniques

What triggers your symptoms at work?

What strategies or techniques will you use to maintain a good working environment? 


\section{Reflection}

The final session will focus on reflecting on the new knowledge and strategies learned throughout the program.

\section{Suggested Discussion Questions}

- What do you feel you accomplished during this program?

- What were the challenges of this program?

- What resources have you found most helpful?

- What are your views of the future and what would you like to achieve?

- What advice would you give others who have a vestibular disorder?

\section{Suggested Activities}

- Activity: My Balanced Day

- Have the individual plan an "ideal day" using handout 6.A. Discuss goals for achieving this day.

- Activity: Reasons to Celebrate

- Discuss reasons to celebrate using handout 6.B. Have the individual add ideas of their own to the list.

\section{- Activity: Continuation of Goals}

- Discuss with the individual a plan to continue with their long-term goals.

\section{Handouts}

- Handout 6.A. My Balanced Day

- Handout 6.B. Reasons to Celebrate 


\section{A. My Balanced Day}

\section{My morning:}

My day:

My night:

Who will be there?: 


\section{B. Reasons to Celebrate}

- Noticing an improvement in symptoms

- Having a symptom free day

- Making it through a difficult day

- Having a successful doctor appointment

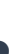

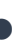

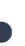

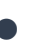

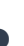




\section{APPENDIX H}

Site Presentation 


\section{Appendix $\mathrm{H}$}

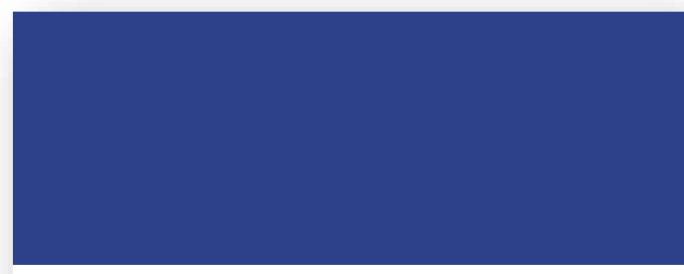

LIFESTYLE MANAGEMENT FOR

VESTIBULAR DISORDERS Michelle Pock, OTDS
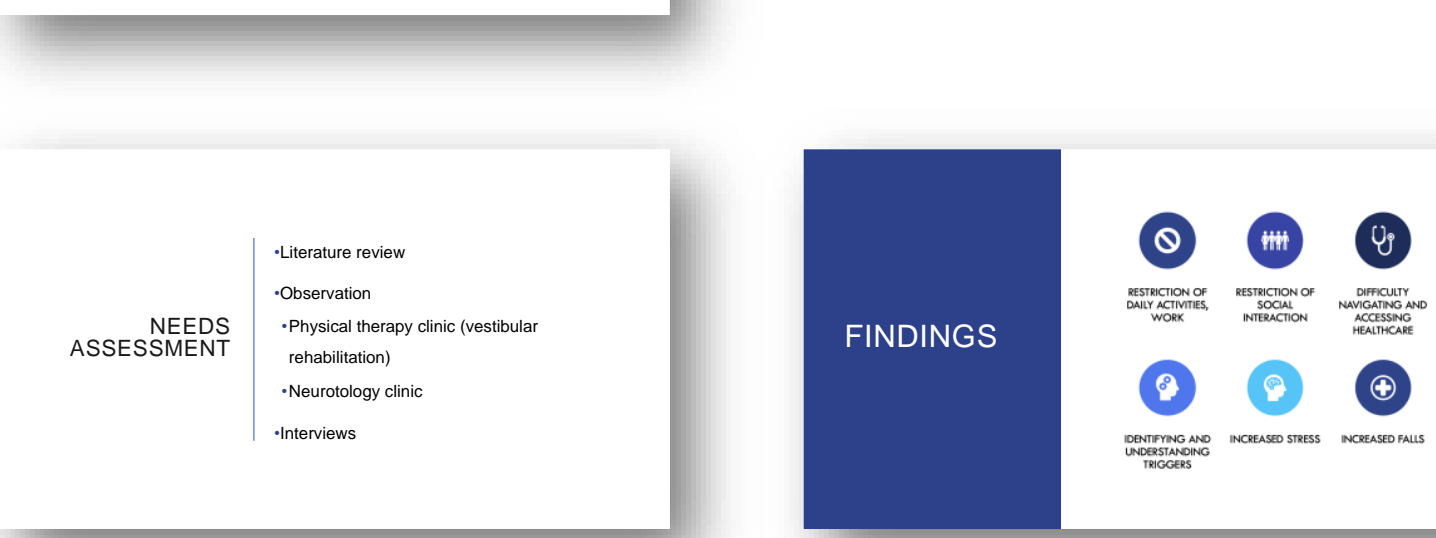

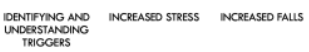

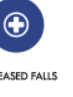

mptom triggers throug movement, activity, and context

-Client education to promote self-management

-Activity modification

VESTIBULAR

-Environmental modifications or adaptations

-Address community participation, driving, and

employment

·(Gronski, Neville, Kannenberg, \& Cohen, 2017)

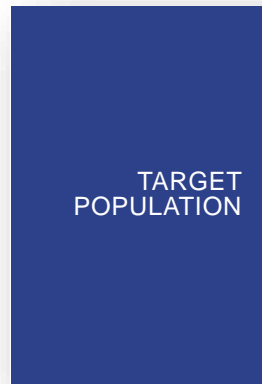

-Adults with vestibular disorder

- Vestibular migraine

- Vestibular neuritis/labyrinthitis

-Ménière's disease

- Perilymph fistula

- Vestibular hypofunction

- Unknown vestibular dysfunction

-Willing to make lifestyle changes

\begin{tabular}{|l|l|}
\hline Module & Topic \\
\hline 1. Vestibular Symptom \\
Management/Self-Management & Baseline \\
Emergency Planning \\
\hline 2. Self-Care and Routines & $\begin{array}{l}\text { Stress Management } \\
\text { Sleep Routine } \\
\text { Eating Routine } \\
\text { Physical Activity }\end{array}$ \\
\hline 3. Health Management and Advocacy & $\begin{array}{l}\text { Navigating and Accessing Healthcare } \\
\text { Medication Management }\end{array}$ \\
\hline 4. Activities of Daily Living & $\begin{array}{l}\text { Home Management and Fall } \\
\text { Prevention }\end{array}$ \\
\hline 5. Community Integration & $\begin{array}{l}\text { Transportation } \\
\text { Social Interaction } \\
\text { Work }\end{array}$ \\
\hline
\end{tabular}

-Lifestyle- characteristics, behaviors, and functions of individuals that influence their physical and mental health (Farrud, 2015)

MANAGEMENT PROGRAM

-Lifestyle factors- diet, sleep, exercise,

leisure, etc

-5 Modules- one session/wk

-Facilitated by an occupational therapist 


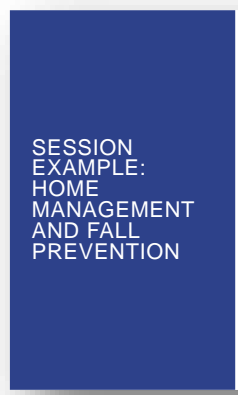

-Vestibular impairment significantly increases risk of falls, which can be costly and increase a person's fear of moving

Goal: To identify home adaptations and modifications to promote ability to perform occupations in a safe environment

Activites

-Activities
$\cdot$ Home Safety Self-Evaluation

- Adaptive Equipment

- Fall self reflection

- Fall prevention education

- Safe body mechanics and energy conservation

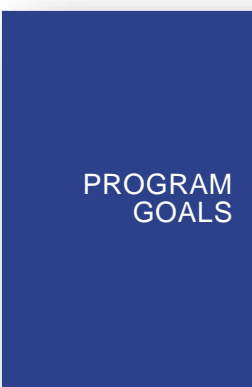

-Address and promote lifestyle modifications in people with vestibular d -Promote health and well-being

-Implement behavior changes into routine -Increase person's engagement in chosen occupations

-Prevent symptoms

Thank you Any questions?

\section{REFERENCES}

Agrawal, Y., Carey, J. P., Della Santina, C. C., Schubert, M. C., \& Minor, L. B. (2009).

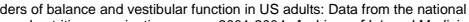
health and nutrition examination survey, 2001-2004. Archives Farhud D. D. (2015). Impact of lifestyle on health. Iranian Journal of Public Health, $4(11), 1442-144$

Gronski, M., Neville, M., Kannenberg. K., \& Cohen, H. (2017). Vestibular impairmen, vestibular rehabilitation, and occupational performance. American Journal of 